\title{
Literary poetic tradition: An archetypal analysis of selected Kagan poems
}

Sultio, Ariel $\square$

Department of Education, Tagum City, Philippines (Ariel.sultio@deped.gov.ph)

Gomez, Dan

University of Mindanao, Tagum, Philippines (dangomez031986@gmail.com)

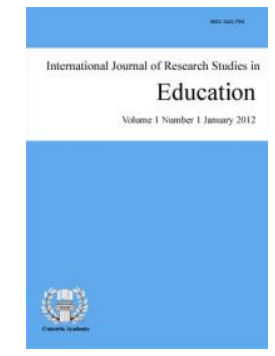

ISSN: 2243-7703 Online ISSN: 2243-771

OPEN ACCESS

Received: 5 February 2022

\section{Abstract}

This study aimed to analyze selected Kagan poems; understand their poem preservation and hopes about their literature, culture and the tribe. The qualitative design using archetypal criticism and phenomenological approaches were employed. Corpora were downloaded from credible resource in the internet and with cultural significance of 14 Kagan tribesmen from Tagum City, Davao del Norte. Results shown in archetypal analysis symbols were: sweetheart, heart, marriage, work, lover, past days, strength of my body, life, world, feast, days and nights, trouble, death, healing, snake, secret, handkerchief, tigers, lions and elephant, cliff, wild chicken, kingfisher and hawk, old woman, old man, oldest boy, water, ring, nice clothes, yellow, tomb, celebration, seventh mountain, river of Jordan, God, horses with wings, golden palace, mosque, gold, old couple and child. For Second research question, emerged themes were: use poems as lullaby, teach poems to the youth, let children repeatedly recite the poems and showcase the poems in social gatherings and special occasions. Last research question elicited themes were: poems and literature be preserved, literature be handed down from one generation to another generation, continuously educate the youth about Kagan literature and practices, use modern technology as archive of Kagan literature, Kagan's cultural identity as tribe be reflected in poems and Kagan literature and cultural practices be appreciated. Hence, archetypal features from the corpora provided that these were culturally significant and universally accepted.

Keywords: teaching English, literary poetic tradition, archetypal analysis, Kagan poems, Philippines 


\section{Literary poetic tradition: An archetypal analysis of selected Kagan poems}

\section{Rationale}

Back in the olden time, poetry played a vital role in the ancient civilization. It was an old but creative way of preserving ones' cultural heritage. Lines in poetry were like different array of colors woven into single and meaningful idea. A type of writing either talked or composed, which highlights musicality, other multitude examples of sound and symbolism, uncounted conceivable ways that words can generate meaning. Kagan tribesmen are astonishingly rich with their imagination and inspiration about the community where they belong and have produced a craft that reflect ethnic significance. The morale and beliefs possessed by the tribe originally rooted in their ancestor's experiences which passed orally down to the next generation (Bascon, 2012; Yu, 2017). Poetry appreciation is a form of uncovering the human life. To illustrate, procedure of verse creation demands the ability of creativity and literary techniques. The output of this artistic work brought critics in the state of roundabout way. At the same time give an opportunity to figure out how to understand and welcome issues of human life and push readers to be more sensible. Despite the importance, it implicates the dark reality as we face the new millennium. These native literary expressions are put in danger and somehow soon are as burnt to the ground because of their total extinction (Brown, 2010).

Alarming concern at hand is the continuous and no action to these undocumented and unrecorded literary works of our indigenous people. As a steward of our native root, this body of literature must be secured purposely of proliferating throughout generations but, sad to unveil it has been neglected and being gradually forgotten as the year changes. In addition, what is more frightening is the depleting historical significance. Therefore, crisis in tribal communities when elders die and likewise together with the language and literature of the ethnic group (Alexander, 2013). Internationally, among the popular celebrated poetry are coming from worlds' literary canon like Europe and America such as "Anabel Lee" by Edgar Allan Poe and "My Last Duchess" and "Sonnets from the Portuguese" of Robert and Elizabeth Barrett Browning. Those poems are just a minute piece of the huge picture under scrutiny. Furthermore, there are still countries with their masterpieces that need to be studied and be able to discover and appreciate on the aspect of formal understanding regarding the oral tradition it possesses (Yu, 2017).

Replicating the situation in the Philippines, a pinch of compiled and recorded Filipino poetry is available which is ironic given the country's sumptuous tradition and culture. Poetry is a manifestation of people expressing their feelings and emotion to man, society, nature, government and so on yet, only minimal are identified despite its vast use. Thus, an urgency to indulge oneself to deep exploration of more oral traditions of our ethnic groups across different provinces. Moreover, a study revealed Mindanao region for instance unleashed a few number of their poems which again stressing the need to conduct more research pertaining to analysis, documentation and preservation of literary works (Eugenio, 2007). Trimming it down in the local setting, the researcher driven by patriotic value was inspired to conduct the study about the Kagan poetry. It aimed to contribute the result to the growing volume of literary knowledge and meaningfully appreciated and read not just here but throughout the globe. Additionally, in the light of Kagan tribe this may raise level of awareness on disseminating the existence of Kagan culture. Notwithstanding, unending neglecting and ignoring these literary works will be put into waste and eternally forgotten along with the poets (Yu, 2017).

Stating it for a fact, in the context of societal changes and culture diversity amazingly, an exploratory study conducted regarding culture components and its intersection with one another found out, the ability to adapt of Kagan in Madaum, Tagum City when it emerges with other tribes. Ostensibly, despite the tribes' being assimilated and acculturated, an interplay of ethnic markers is used to identify the ethnic identity by which language is the primary and vital marker as a distinguishing factor to someone be part of the Kagan Community. Nevertheless, language is not the sole basis of Kagan group. Another thing is the genealogy, which traces the 
origin and history. Moreover, Kagan individuals belong to a single group of indigenous people in defiance of dereliction of sect, share customs and material culture. Importantly to highlight, that Kagan is a distinctive group and does not under the umbrella of the Tagakaolo which other assumed. Notwithstanding, urbanization is the social problem which resulted to vulnerability of their culture to change, loosening of social control and exposure of the youth to the western lifestyle. Thus, documentation and proper recording of Kagan poetry as an enigmatic print of the race must be accomplished before all of these turn to ashes (Bayotas, 2004; Lobos, 2000; Peloton, 2001).

In addendum, Archetypal is an extraordinary literary criticism in analyzing verses of ethnic poems. This approach is piloted by Karl Jung. The archetypes of poetry, seeks to identify similar motifs and themes found in multiple mythologies and recurrent patterns of imagery which are essential in poetry criticism (Guerin et al., 2010). Previous studies focus on exploration of culture, identity, development and emergence of Kagan tribe. However, I have never come across similar study which certainly discussed about Literary Analysis of Kagan Poems. Further, this will add relative concepts and ideas which may positively impact the academe. The investigation revolves around the nature and salient features of Kagan poetry which is guided by Archetypal Analysis.

\subsection{Purpose of the Study}

The purpose of this phenomenological study was to describe and understand the magnificent poetic tradition of the Kagan tribe in Tagum City, Davao del Norte through analyzing their poems. Another focal aim was to safeguard their written and spoken poems and made these documented well for the purpose of securing literary meaning and quality. This was to ensure that their literary works were preserved and appreciated by the forthcoming generation and be utilized in academic purposes much more as a basis for future research. At this facet of research, documenting and analyzing the poems of Kagan tribe in Tagum City was the primary concern. Documentation and proper recording has been implored to attain literary preservation. By critical analysis of selected Kagan poems under archetypal approach had elicited knowledge and cultural significance of Kagan symbolisms in their poems. The historical and societal association of poem symbolisms among Kagan achieved the universal meaning of their archetypes.

The success of this phenomenological study would be a significant contribution to the growing body of literature. Aside from this, was to discover and record the unique practices of the Kagan tribesmen in the preservation of their poems for the purpose of proliferation. Likewise, the purpose of this study was to reveal the Kagan insights and aspirations towards their poetry, literature and to the tribe as a whole. Since, they were given the chance to showcase their unheard oral and written traditions. This was a great way to appreciate the poems by the students through the Kagan overview. More to add, this study visualized documenting Kagan poems. And also, poem preservation and understand the multi-facets Kagan folks' hopes and insights through the research process in an in-depth interviews and focus group discussion either constructively or destructively straight from their locale Tagum City, Davao del Norte. Thereafter, this can be a pattern of curriculum development as part of teaching Philippine Literature in the academe.

\subsection{Research Questions}

This study delved on the Literary Analysis of Kagan Poetry in the City of Tagum Province of Davao del Norte. Critically, it answered following the salient questions:

$>$ What are the literary features of the Kagan Poetry using Archetypal Approach?

$>$ How do the Kagan tribesmen preserve their Poems?

$>\quad$ What are the hopes of the Kagan tribesmen about their Poems and Literature as a whole and to their race? 


\subsection{Theoretical Lens}

This study is anchored on the critical approach of the great psychologist-philosopher Carl Gustav Jung (1955), "Archetypal". He emphasized that every individual shares universal collective unconscious. It is a set of primal memories collective phenomena like: sun, moon, fire, night, and blood the archetypes consequently this trigger the collective unconscious. He believed that humans share common knowledge of ideas, images and emotional responses. An integrative and interdisciplinary interaction of insights from Anthropology, Psychology, History and comparative religion, mythological approach explores writer's common humanity through outlining the human imagination which uses myths and symbols similar to any types of culture and era. Therefore, the Kagan oral and written poetry is best suited under this literary approach (Gioia \& Gioia, 1995).

To elaborate, an Archetypal pattern in poetry hypothesizes racial memory and archetypes. This proposed that behind personal unconscious is what we call the primeval collective unconscious. It is the shared cognitive background in every human family. Essentially, archetypes are no natural to the human mind but rather it is a predisposition as a response to a certain stimulus. In the view of psychological reflection, mental instincts have implanted to human intellect indefinitely in harmony with the symbolic wisdom. This institutionalizes that these symbols and patterns recur across various cultures and all time. Meanwhile, archetypes in literature and art is a character, a tradition, an event, a story or image reappear in different cultures across a periods of time. Further, Archetypes can be seen as or in the form of stories, characters, and symbols and must be universal. Thus, literature imitates the total dream of humankind and not the world around us (Jung, 1955 \& Walker, 2002).

Further, Archetypal approach determines form and function of literary piece and text's meaning is duly constituted by cultural and psychological myths. These are the enigmatic forms which personified and concretized in a repetitive image, symbols, or patterns, motifs, recognizable characters. Likewise, under archetypal images and story patterns inspire readers to make involve ritualistically of beliefs, fears, and anxieties of their generation. The archetypal features both constitute intelligibility of the text and tap into a level of desires and anxieties of the people (Delahoyde, 2011)

First supporting theory is Mythological criticism (Guerin et al., 2010; Gioia \& Gioia, 1995) valued prehistoric and biographies of gods and examines the inner spirit that provides that form resulting to vitality and enduring appeal. This looks on the recurrent universal patterns present in most literary works. It is an integrative insight among anthropology, psychology, history and comparative religion. The focus is on the writer's common humanity by discovering the individual imagination using these myths and symbols. Under this criticism archetype is a key concept like as: symbols, character, situation, or image that a deep universal response. More so, this criticism works historically, which displays vitalizing and integrative forces lifted from the complexity of humanities collective psyche. Important to highlight, archetypal critics use mythological approach to magnify a literary works in a broader context of works sharing a similar pattern.

Second, Psychological criticism (Biddle \& Fulwiler, 1989) supported Archetypal approach through exploring areas of wish-fulfillment, sexuality, the unconscious, and repression and understanding the role of language and symbols in demonstrating the ability to reflect unconscious such as fears and desires. The emphasis was on the dilemmas and conflicts in a given piece which attempt to read the author's own family life and traumas into the actions of their characters and this can be expressed through principles of: condensation, displacement and symbolism.

Third is New Criticism (Augustyn, 2018) supporting Archetypal, it communicates feeling and thought that cannot be translated into language. This set aside to define and formalize qualities of poetry, language, and implore close reading which emphasize the connotative and associative values of words and the multitude functions of figurative language such as: symbols, metaphor, and image.

Important to emphasize, archetype refers to first print meaning images in the human mind present since the dawn of time. This point of view considered as the building bricks of the consciousness which are recurring in 
literature, art, and architecture of various cultures around the world. To illustrate, the imagery of mandala or wheel considered to be the oldest archetype because of its replication and available to the unconscious not only to anyone but also on a collective level (Jung, 1968).

Thus, symbols are those of common to the majority and of the same meaning. Collective symbols for example which are common to all cultures and there is no likelihood and other interpretations are: sky father and earth mother, light, blood, up-down, the axis of a wheel and others. In like manner, imagination is the authentic contributor to the core nature of the world or viewing the particular as somehow embodying a more universal significance (Wheelwright, 1959).

Archetypes viewed as extensively a complex amalgamation of genre or kind of literature. Accordingly, it has major phases of seasonal cycle namely: comedy, romance, tragedy and irony. To show the relation of myth and archetypes, the former is said to be structural organizing principle of literary form while the latter, is essentially is an element of one's literary experience. Mythology gives us a diagram or blueprint of what is literature and talks generally; ingeniously of human situation narrating from alpha and omega, from the height to the depth, which is imaginatively conceivable (Frye, 2006).

This phenomenological study concentrates on the analysis and synthesis of Kagan poetry as a part of the ethnic community. The study's deep concern in preserving and documenting these valuable literary works will pave to the better understanding of the tribe through the poems. This will also provide analysis on the literary features of the Kagan poetry using Archetypal Approach.

\subsection{Significance of the Study}

Indigenous people of our society are most of the time not given the opportunity to showcase their literary works and seldom studied. If this practice continues such the undocumented and unpreserved native pieces of Kagan tribe, was not impossible that in the long run this gradually be forgotten. The old way of oral tradition of handing over information, knowledge and literature posed danger to its survival. To highlight, this even made harder to preserve and safe guard this rich cultural and literary heritage. Moreover, this phenomenological research found its urgency to conduct and significantly provide beneficial understanding about the above-said tribe. Primarily, the focus of the study was on the poetry analysis of Kagan. It was an interpolation between the selected poems with the symbols and how these related to the people and other culture. The symbiotic effect constitutes the unique culture of the tribe. Apart from this, it was a reawakening of their ethnocentric point of view towards their ethnic identity rather than general patronage of western culture. This emphasized that they need to see pride and honor within themselves. On the contrary, it was a delicate but sensitive study to deal with misrepresentation was under penalty of laws. Secondarily, the government sector in general took a major part as a benefactor of this study. Being the one commissioned to conserve, nurture and above all protect the Kagan tribe. Therefore, as leading agency genuine concern and support about their social development was a must. Hence, frontline participation in appreciating, documenting and stewarding valued trace of their race - poetry.

In the same manner, this rippled in the educational sphere particularly, learning Philippine Literature. This served as a springboard when it comes to Kagan poetry. This made the educational institution one of the direct beneficiaries of the study. Thereupon, teaching culture uniqueness while introducing a kind of poetry. To add more, this validated the genuine value the National Commission for Culture and the Arts (NCCA) have on its records. Also, crossed section of our society would be provided with collected data pertaining literary variety. The repertoire of cognitive aspect lifted may be a flat form of appreciating, understanding and respecting each one's custom, culture, tradition and literary writings. Much more, this will enlightens and inspires future researchers to delve deeper and conduct researches with a similar concept but, on other perspectives of the Kagan tribe. This study will aid future researchers may also use this as a point of reference to know more about the Kagan. 


\section{Literature review}

\subsection{Tracing the Kagan Tribe}

In this segment of the gathered review of related literature presented are the important information and background of the tribe under study - Kagan. The Philippines has a vast range of ethnic groups. As per record there are One Hundred Ten (110) considered as major indigenous groups in the country. To highlight a single group "Kagan" is one of them, rooted from the word Ka'ag historically means "to inform or to warn". Accordingly, the name was actually ascribed by the people themselves and not by the other individual. The purpose was not to give them the identity but to warn the foreign invaders during those times such as the Japanese, Americans, Spanish, Muslim and Chinese. Another etymology of Kagan tribe is from the Mansaka of Compostela Valley the term was came from the word "kyakarag" or "to warn" and the other one is "mangaragan" or "headhunting tribe". Moreover, there was this entity coming from Tagasug that uttered, "Kyalagan ko na" meaning "I have found it" directly referred to Kagan, that is why the former was named as Kalagan because from the word Kyalagan (De Vera, 2007; Poraz, 2001).

Important to underscore, that large population of the Kagan tribe is living mostly along the Davao gulf and modern-day barangays of Madaum, Liboganon and Busaon as well as long the Tagum-Liboganon River that meandered around Pagsabangan, Canocotan, Bincungan and Liboganon and Hijo River that flew thru Apokon, Tipas (now part of Magugpo East), and Pandapan. Kagan is said to be Tagakaolo who is Plater on embraced Islam through intermarriage or through socialization among other Islam believers. Although, some people would characterized Kagan as Muslims while Kalagan as non-Muslims, this religious distinction would not deny the fact that both were ethnolinguistically of equal value and referring to one group. In addition, Kagan clan were involved in agriculture others were in to wage labor while living in coastal areas were doing fishing and some were laborers in plantations (Gowing, 1984 ; Tiu, 2005).

\subsection{Culture and Tradition of Kagan}

Presented hereunder are the rich culture and tradition of Kagan as a unique member of speech community. Before the coming of Spaniards, households along Hijo River were prevalent. This was called "Iyo" accordingly this means a Kagan chant. This was used for communication among the Kagan tribesmen through an imitation of sound the Antolihao bird. To illustrate, a word will be chanted out loud and likewise member of the tribe should shouted back in response by this, tribal identity can be recognized of the newly-arrived tribesmen which served as the key to enter the community (Makaigad, 2018). An example of Kagan poems are O, Kay Pasaya or Oh, Sweetheart talked about the lover's forever commitment of his/her love and affection towards his/her lover that wherever he/she goes the love remains. Magaokano Ako or What Shall I Do dealt with the lover's praying to be remembered by his loved one and not to be forgotten. That despite the distance and space may his lover still committed and treasured their promised love for each other. Yang Otaw Magkaombok or People who are in Love talked about a couple who were deeply in love to each other and were so overwhelmed with their passionate feelings without noticing that time has passed and everything has come to an end. That time is inevitable as to death is unavoidable. These are all example of love poems (Institute of Nat'l Language Ministry of Education, Culture and Sports, 1984).

Although, huge trees such as Durian, and Baluno the same as Bamboo grass were used as a territory markers. Kagan's markers also included stones used to note sacred places for burial and worship area. Their common symbols for burial grounds were tombstones, Jampaka or Kalachuchi and Kila. On the other hand, Kagan, Mansaka and Mandaya shared a common culture of valuing the conduct of rituals and named the same God. Their God named as "Tagallang na Magbabaya”. In like manner, the two tribes also lived along riverbanks. After all, their source of living is also fishing and farming (City Gov't of Tagum, 2019). More so, Kagan tradition dictates, the community was ruled by a Pyagmatikadung / Datu together with his Council Elders which helped 
him to the general affairs of the community. When there was a problem, like the usual government, customary laws and other major cultural and traditional practices will precede the conflict. The lineage of Kagan Datus started in the $18^{\text {th }}$ century. However, before the foreign invaders political governance was already established. Accordingly, the first Kagan leader was Datu Daugdugan and Datu Mangkiyas lead the Madaum on the other side. The succeeding Datu were Datu Belalang, Datu Pampanng, Datu Malila, Datu Arimao and Datu Bungad respectively (Bungad \& Pongo, 2018).

In addition, political structure of Kagan was also composed of the Kuwano a warrior tasked to maintain peace and order and assigned to protect the community. Another personality in Kagan was the Balyan the tribe's healer, spiritual leader and adviser. He was ascribed as the administration of the traditional medicines. Further, he was a custodian of ceremonial laws who performs the ritual and other spiritual ceremonies. The Biya a woman leader coming from the royal blood. She can be the wife, an aunt or a younger sister of the Datu who was a prerequisite to be knowledgeable and a having a good wisdom to take better care of the women's affairs (City Gov't of Tagum, 2019). Conversely, the Kagan population declined when they have resisted the rule of foreign-led government where many Kagan or Moros as named by Spanish people, had been wiped out. Further, their population even reduced when the Malaria outbreak took into place that was during the Japanese regime. At present, Kagan people can be located in Barangays of Madaum, Bincungan, Busaon, Libuganon, Apokon and San Isidro (part of Madaum) and portions of Magugpo East formerly Tipas. Traditionally, these were Kagan's territories and oral traditions revealed that these places are Kagan terms (Bungad, 2018).

Furthermore, the word coinage of places rooted from Kagan language were Madaum, Liboganon, Hijo River, Tipas, Busaon, Bincungan and Apokon. Madaum came from the word "Madwm" meaning lowland. This is pronounced as "Madwm" by the Mansaka tribe in the ancient time. To use this in an utterance "adtu kita sang Madwm magbaw-baw" translated as "Let us have a meeting at Madwm" (Bungad, 2018). The Liboganon got its name associated by the original settlers because of the presence of small ponds during low tide which named as "libug". This was also present nowadays on the uncemented roads in the barangay (Lapana, 2018). Tipas was named after the child born in the said place named as Tipas (Baloyo, 2019). Moreover, Busaon came from the word "busaw" meaning evil spirits which have plague the place. Since Busaon was wooded area, thus, open for dwelling place of the unseen elements (Famindang, 2018). Bincungan on the other hand, rooted from the word "bingkung" which refers to the curved direction of the river (Byatan \& Indie, 2018) lastly, Apokon came from the word "apok-apok" which means powder dust from the skin of bananas planted abundantly along the banks of the Iyo river (City Gov't of Tagum, 2019). Thus, historical and geographical background of Kagan people were important to discuss primarily because this was the subject matter at hand and the identified research informants.

\subsection{Role of Oral Tradition in Culture Preservation}

This portion shows the integral role of the Oral Literature or Tradition in the Culture Preservation as it passed through from generation to the next. Significantly to establish, handing over from generation to the next of different forms of culture is vital to secure its preservation. This is done through oral literature which is useful in so many ways to a tribe. By this practice, human behaviors and characters before were saved such as: social trusts esteems, capabilities, knowledge and the vast historical phenomena of the society. Thus, the oral tradition helped the future to acquire and learn the things that have been done before and still perform the same (Kothari, 2014). In addendum to the same, the assurance of successful transmission of one's culture and tradition to the next offspring greatly depend on the correct practices of the predecessors. The execution of innovative works of verbal workmanship to wit: Ritual writing, social stories, healing serenades, epic lyrics, melodic sorts, tunes, myths, legends, recreations, life histories or verifiable accounts. To present a good illustration was the African Oral Literature wherein, the imprint of those traditions were preserved through a perfect, in quality, historical value and viewpoint whereby Africans viewed themselves customarily and find solace despite serious social and different struggles (Finnegan, 2012).

Explicitly, the association between Oral Tradition and society was delicate and not the same. But in the case 
of African Oral Literature it was evident that there exists a mystifying oral craftsmanship of the above literature. Evidently, before or even nowadays oral literature serves as a vehicle of spreading news, thoughts, information and history. Generally, Oral Literature is used by the people in order to safeguard the society's history and development through the ages (Turin, 2013). In like manner, oral tradition helps to attain social society through training and dialect. Accordingly, Oral Literature such the used of drums, melodies, show and serenades were the things utilized to transmit the conventions from generation to generation such as social characters and society development things like these happened in Tanzania (Omari, 2010).

To connect, Oral Literature consisting of moves, cheat, monstrosities or beast, legend and tunes present in Sukuma pictured the transmission of societies from one age to the next. Subsequently, without hesitant Oral Tradition plays an integral part to the people when it comes to transmitting of culture since it keeps the historical backdrop of the society. For instance, the Sukuma Oral Literature such as adages, questions, stories lyrics, myths, melodies, supplications, move and plays on words, it can be infer that in Oral Literature in Sukuma fill the need, for example, to instill positive esteems; warm, relieve, engage, applaud and energize individual from the general public. In this particular Literature craftsmanship can never be viewed as workmanship. This creates a bind to the people that create and perform. And no matter what whether recounted, described or sung build a purpose to the tribe.

Oral Literature is utilized to instruct and engage individual to the general public. In the given literature it can be established that society and even now educated about their way of life and truth of life through kinds of Oral literature as per the events. Important to emphasize, that Oral Literature caused them to grow up as indicated by the societal desires. Therefore, Oral Tradition or Literature exemplifies history, social esteems, logic and accepts of the general population (Chesaina, 2011). To add, a study conducted about the imilolozelo or lullabies of Zulu children's poetry and considered to be the ancient form of African literature. And like all poetry and folksongs of societies were transmitted orally. Further, it was pointed out that these were practiced to teach and bring people together. In which, this performances of poems as cradle songs or an oral art form does not only play to lull children to sleep but likewise, contributed to the upbringing, socialization and development of a child (Ntuli, 2013).

As a supplementary, in the case of Aboriginals the use of oral tradition among the group is not just done through accounts and tunes but at the same time with the arrangement of principles and conventions purposely for transmission. These principles were the guidance to comprehend the contrasts between the information, learning and motivation that were passed to the next generation. Melodies and stories for instance, which owned by a deceased author and have not recorded and utilized may brought a problem in putting into disciplines. By that, the importance of these devices in recording and safeguarding the information and social customs of the Aboriginals will ensure that present generation would utilize the same. The culture of Aboriginals transform into print, sound or visual frame though clashed with their conventions. Furthermore, a technique and adjustments are made for recording by some member of the group and have acknowledged the new methods to safeguard their insight and conventions, thus far, they maintained their customs and standards (Kombo, 2014).

Thus far, the non-Aboriginal observers performed stories and tunes just for it however, the Aboriginals speak the two-route channel wherein the information goes between the entertainers and the crowd. Wherefore, the performers suits for this situation since during the stylized social gatherings and in the event of customary occasions, stories accompanied by the different correspondence to wit: moving, painting, or simply consistent exercises between the entertainers and their audience, and so, generally it is emphatically connected with the conventional daily living of the Aboriginals (Rothenberg, 2011).

\subsection{Literary Poetic Tradition}

At this point, presented herein the general insight, background and knowledge in connection to Poetic Tradition. Ostensibly, the word poetry appreciation highlights the appraisal of verse as an abstract work. The 
poetry reflects the humanity; nonetheless, in composing a poem it extensively requires the poet's innovativeness and creativity. Most themes in poetry dug on the issues of human life at the same time re-communicate them by means of fiction as verse, short stories, books or show. Along the composition of each line in a poem constant innovative is ceaseless. Poet has the one in control, create and manipulate the issues of life that he or she wants to implore in various characteristic and facts of fiction. Writer can do everything possible in writing but not in reality in a piece and make it be unpleasant and agonizing to produce a good review. Therefore, by way of writing creatively can make the readers puzzle and really need to use their critical thinking skill to uncover the author's message in any forms of poetry. Likewise, poem can make the readers to become more sensible (Brown, 2010).

Furthermore, appreciation undeniably interconnected with an expression, the same as poetic gracefulness has something to do with verse exercises. A scrutiny of sonnets, which is under investigated, unlocked how to be grateful in poetry. In this manner, it figures out the way in composing, present and audit lyrics have been created. Critically performed this task, a reader understudy will understand the verse implicitly and explicitly with full of gratefulness. In this state, the reader himself will put on the writer's shoes, wherein he or she can feel, empowers to ingest esteems in lyric, and acknowledges verse as show-stopper along with its magnificence or shortcoming (Morrison, 2012). Henceforth, graceful appreciation provides the readers with self-thankfulness and feedback. People who are convinced of being thankful towards verses are persuaded as well of being attractive to consider things when it comes to creative energy, innovativeness and creation. Wherefore, this energy towards verse is "honor for verse or a consequence of acknowledgement, understand, translation, thankfulness and happiness pertaining to work bolstered by the inward affectability of qualities in the poem" (Pingel, 2013). Likewise, part of the restrictions was the affectability to recognize an artistic piece such as verse will bring college understudies to distinguish, understand, capacity to decipher, capacity to live and appreciate abstract work. Moreover, there are four levels of verse thankfulness: level of affection, level of pleasure, the degree to respond and level of profitability. Thus, a feeling of verse gratefulness is an abstract honor that is bolstered by internal affectability esteems in verse, making one be able to perceive, understand, translate, acknowledge and appreciate the artistic work (Tarigan, 2014).

\subsection{Language and Literature}

This part provides writings about the interpolation and general information of Language and Literature being the big umbrella of literary analysis. Apparently, literature intertwines with culture when under study. This constantly go alongside in different fields of sciences and philosophy most importantly to history by magnifying humanism, human sciences or history. In the present generation, the world view focused on the wide social examination and the way that abstract writings were composed in dialect is a moderately ignored thought. Anyhow, scholars have conducted researches dealing with the write ups in the dialect specifically examining both in its outward or recorded frame discourse, composition, screen content and its internal appearance of reflection, cognizance and neuroscience (Culpeper, 2011).

What was more, socially substantial and esteemed type of dialect is viewed as being settled in frame as composing or open engraving. Nevertheless, a performative perspective allowed dramatization, theater and readings out loud of verse and writing to be included inside the thought of the abstract. Different frames mixing verse and believable workmanship, recitation and move, and even citation inside design and agriculture can be viewed as even less the same cases. Be that at is may, the guiding genuine imprint of writing as a form of composition in printed material has empowered a perspective of scholarly investigation in principally formalist facet after that it is considered in writing the dialect used (Cook, 2010). Hence, language restriction has been limited to the physical content most especially the etymological conventions of an abstract examination.

Non-formalist in the case of the use of dialect should carefully ponder on unchangeable part of the dialect framework would be the usage of prompt and general social and ideological setting, inventive authorial recognition and inspiration, and the procedures and preferences of a reader or perusing group (Cockroft, 2012). 
Therefore, literature is an imperative zone inside subjective science. Writing is common type of dialect being used, both exceedingly universal and communal persuasive as writing in all forms of demotic such as prevalent verses and verses, equation fiction, trashy books, cleanser musical shows, most love great peruses and other published stories and verse website. Abstract investigation is a byproduct of these critics and pool of experts in academic articles and intellectual press who were dependent to online surveys of books and perusing gatherings, arrangement of top choices and all way of casual perceptions on writing through the ages (Burns, 2015). For that reason, literary analysis as part of literature focuses on the broader dialog regarding dialect structures and impacts have been directed. Abstract works unpretentiously highlight casual talk and at the exploratory edges of what was conceivable in dialects and artistic dialects in all its completely contextualized assorted variety. Thus, it ignites the mind of psychological researchers to comprehend human correspondence legitimately (Barsalou, 2015).

\subsection{Poetry Analysis as an Instrument for Culture Understanding}

Presented hereunder, are related studies that highlight Poetry Analysis as a tool to transcultural understanding. In light with that, poetry is an effective and at the same time creative way of expressing romantic feeling towards the opposite sex as part of communication. In the stage of courtship, the initial stage of it is through an exchange of poetry. When it does not, like in "kaimami" scenes or physical encounters, here, the passionate male shows as with breaking social convention and breach of etiquette is further clarified through highlighting the unusualness of the resulting relationship. It is explicit that without poetry romantic relationship would be impossible since it elicits emotions and feelings from both sexes. Poetry is feasible to achieve romantic relationship among any other platforms amongst men and ladies. In all cases of romance, it all started with a creative trade of verses. But, in the scene of "kaimami" the in loved male broke the social tradition, and his change of manners was cleared up through featuring the bizarreness in a relationship. Thus, in the absence of verse, advancement of sentimental connections would be outlandish (O'neill, 2012).

Similarly, in the case of Japanese verse "waka" which contributed to the history of verse in the Heian period. The "waka" verse was patterned in the Chinese styles formed through different sorts of verse. The most critical of these sorts and that which was traded between individuals from the Heian gentry, was "tanka" consists of thirty-one syllables written in 5-7-5-7-7 lovely meter. Unlike "waka", "tanka" does not have the signified articulations compared to the former. In addition, the conventionalized syllable tally has remained for all intents and purposes in place, protecting "tanka" as a beautiful shape. The usage of this kind of verse "tanka" for communication possible solely to those privileged individuals (Morris, 2011). Moreover, the Japanese writer Ki no Tsurayuki introduced the few but fundamental parts of "tanka" and he also sets up the idyllic beliefs and traditions which was epitomized by the Heian privileged people in their verses. This verse did not serve only as a blue-blooded diversion set apart by piddling triviality. Or might be, this workmanship was because of one's spirit and depicts his extraordinary and developed feeling. This idea is alluded to as the "full of feeling expressive" perfect, which all Japanese verses were based and judged according to it (McCullough, 2010).

Wherefore, Ki no Tsurayuki who has created the intense Japanese prelude has a further Chinese compliance where he presents a couple of central parts of "tanka". Significantly, he formulated the pure convictions and conventions which is exemplified by the Heian affluent in their verse. This verse did not served just as pure preoccupation set apart by technicality. Again, the flawless workmanship was an evidence of man's soul and made a reflection out of his exceptional, created feeling. Implicitly, this overflowing expressive flawless of feeling and the idea of all Japanese poems were criticize base on it (Cranston, 2012). Henceforward, since 1960s a studying about Asian American Poetry this characterizes transcultural intertextuality as an outskirt crossing practice that drawn in different histories and interweave components from an extensive class of social and scholarly conventions (Said, 2010).

In connection, provided in Xiwen Mai's research considered the artists' formal systems as methods as basis in social talks on national, international dealings, sexual preferences, and ethnic personalities and direction of 
wonderful shape, shifting from customary verse to trial writings. Furthermore, after series of extensive investigation on the writer's verse, unveiled the sublime talk of movement that intersect semantic national and social outskirts, this outstrips the worldview of focus ethnic writing within national limits and obliged the use of transcultural and intertextual reading traverse national and social limits (Caplan, 2011). Therefore, the research highlighted the importance of considering poetry as a vehicle in transcultural measurement of Asian North American writing. In view of the foregoing issue of transnational Asian North American investigation, it was found out how ethnicity and ethnic composition should and must be comprehended in a web of worldwide and intercultural relations (Silliman, 2011).

\subsection{Archetypal Criticism}

Provided herewith is the theory or approach that supported the claim and where the study was anchored about poetry analysis of Kagan tribesmen. This phenomenological study was on the critical approach of the great psychologist-philosopher Carl Gustav Jung, "Archetypal”. He emphasized, every individual shares universal collective unconscious it is a set of primal memories collective phenomena like: sun, moon, fire, night, and blood. The archetype consequently triggers the collective unconscious. He believed that humans share common knowledge of ideas, images and emotional responses. Archetypal approach is an integrative and interdisciplinary interaction of insights from Anthropology, Psychology, History and comparative religion, mythological approach. This explores writer's common humanity through outlining the human imagination. It uses myths and symbols similar to any types of culture and era. Therefore, the Kagan oral and written poetry are best suited under this literary approach (Gioia \& Gioia, 1995).

Feature of archetypal criticism suggested that a symbol is categorized as an archetype only if it is true to all or generally accepted. This means that symbols are universally accepted among other cultures, tribes, countries and different times. Thus, the soul of archetypal analysis focuses in the recurrence of a particular symbol (Jung, 1968). Furthermore, Archetypal patterns in poetry hypothesize racial memory and archetypes. This proposes that behind personal unconscious is what we call the primeval collective unconscious. It is the shared cognitive background in every human family. Essentially, archetypes are no natural to the human mind but rather it was a predisposition as a respond to a certain stimulus. In the view of Psychological reflection, mental instincts have been implanted to human intellect indefinitely in harmony with the symbolic wisdom. This institutionalized that these symbols and patterns recurred across various cultures and all time. Meanwhile, archetypes in literature and art is a character, a tradition, an event, a story or image reappear in different cultures across a periods of time. Further, Archetypes can be seen as or in the form of stories, characters, and symbols and must be universal. Thus, literature imitates the total dream of humankind and not the world around us (Jung, 1955; Walker, 2002).

To support the claim, Mythological criticism as relevant to Archetypal analysis valued prehistoric and biographies of gods and examines the inner spirit that provides that form resulting to vitality and enduring appeal. This looks on the recurrent universal patterns present in most literary works. It was an integrative insight among anthropology, psychology, history and comparative religion. The focus is on the writer's common humanity by discovering the individual imagination using these myths and symbols. Under this criticism the key concepts in understanding are symbols, character, situation and image that elicited a deep universal response. More so, this criticism works historically, which displays vitalizing and integrative forces lifted from the complexity of humanities collective psyche. Important to highlight, archetypal critics use mythological approach to magnify a literary works in a broader context of works sharing a similar pattern (Gioia \& Gioia, 1995; Guerin et al., 2010).

Relative thereto, Psychological criticism supports Archetypal approach through exploring areas of wish-fulfillment, sexuality, the unconscious, and repression and understanding the role of language and symbols in demonstrating the ability to reflect unconscious such as fears and desires. The emphasis is on the dilemmas and conflicts in a given piece which attempt to read the author's own family life and traumas into the actions of their characters and this can be expressed through principles of: condensation, displacement and symbolism (Biddle \& Fulwiler, 1989). Moreover, in the optic of New Criticism supporting Archetypal, it was communicated 
feeling and thought that cannot be translated into language. This set aside to define and formalize qualities of poetry, language, and implored close reading which emphasize the connotative and associative values of words and the multitude functions of figurative language such as: symbols, metaphor, and image (Augustyn, 2018).

In the view of Archetypal approach, it determined form and function of literary piece and text's meaning is duly constituted by cultural and psychological myths. These are the enigmatic forms which personified and concretized in a repetitive image, symbols, or patterns, motifs, recognizable characters. Likewise, under archetypal images and story patterns inspire readers to make involve ritualistically of beliefs, fears, and anxieties of their generation. The archetypal features both constitute intelligibility of the text and tap into a level of desires and anxieties of the people (Delahoyde, 2011). Moreover, an archetypal mantra stressed that an intuition was the key tool to unlock the messages of an art. Wherein, intuitive imagination was the important factor which will enlightens the work of art accompanied with meaning interpolated to Blake (1954), intuition was communicated through symbols, visions, and dreams have contributed to poetic language by imprinting to the myths and rituals of humankind. Significantly, unitive experience was a prerequisite in order to aspire to an expanding vision and avoid the conflict within oneself. To highlight, imagination was important as well as work has to take place within, where the psyche can speak and act, this was in relation to poetic genius (Digby, 1957).

Considerably, in archetypal analysis the individual and the universal forms of an image are identical. And so, this underscores the Jungian theory of collective unconscious. Archetypes are element in a piece of literature such as character, image, narrative formula, or an idea where can be assimilated as a larger unifying category. The classifications of archetypes are those as human, animal, vegetable, mineral and unformed or chaotic worlds, wherein individual symbol represents the communal ones. Guided by Blake (1954), this poetry is what we call as the language of allegory which became the foundation for a new critical understanding of literature. The framework of archetypal symbolism is to unify in our minds the symbolism of another poet, which was anchored to visionary symbolism (Frye, 2006). Literally, archetype refers to first print meaning images in the human mind present since the dawn of time. This point of view considered as the building bricks of the consciousness which are recurring in literature, art, and architecture of various cultures around the world. To illustrate, the imagery of mandala or wheel considered to be the oldest archetype because of its replication and available to the unconscious not only to anyone but also on a collective level (Jung, 1968).

Consequently, archetypal patterns in poetry demonstrate ancient symbolism which was replicated in literary pieces across a long period of time such as Aeschylus, Dante's Inferno, Shakespeare's Hamlet, and Coleridge's The Ancient Mariner. In this perspective, it stresses archetypal view rather than mythological criticism that there was trans historical collective unconscious that was present across literature of various cultures. Important to emphasize, certain poems hold with a special emotional significance through excitation of unconscious forces known as archetypes which are recurring, primordial, inherited images that determine as individual's present experience. This claim was tested among classical and Shakespearean literature that reveals different archetypal images that recurred in the writer's minds (Bodkin, 1965). Magnifying in a deeper lens, symbols are those of common to the majority and of the same meaning. Collective symbols for example which are common to all cultures and there is no likelihood are: sky father and earth mother, light, blood, up-down, the axis of a wheel and others. Important to point out, imagination is the authentic contributor to the core nature of the world. (Wheelwright, 1959).

Likewise, archetypes viewed as extensively a complex amalgamation of genre or kind of literature. Accordingly, it has major phases of seasonal cycle namely: comedy, romance, tragedy and irony. To show the relation of myth and archetypes, the former is said to be structural organizing principle of literary form while the latter, is essentially as an element of one's literary experience. Mythology gives us a diagram or blueprint of what is literature and talks generally; ingeniously of human situation narrating from alpha and omega, from the height to the depth, which is imaginatively conceivable (Frye, 2006). To sum it up, this will be an essential avenue to put into spot light the literary and cultural background of the Kagan people in Tagum City. Readers were given salient features of their poetic tradition as a unique member of the ethnic groups in the country. In 
like way, this will venture the archetypal features present in their poems and document the existing poetic pieces of the tribe.

\section{Methodology}

Research Design - This qualitative-phenomenological approach used literary analysis to distinguish the Archetypal features of Kagan poems and their insights present therein. It is under qualitative research because the data collection is in the field where the respondent or participants experience the problem under studied (Creswell, 2013). This phenomenological study is a research inquiry where the researcher described the lived experiences of people concerning a certain phenomenon being described by the respondents. The above statement culminates in the essence of the experiences of individuals whom all experienced the phenomenon. This pointed the multiple perspectives of the event and creates generalizations of what was something like. As such, it greatly dependent almost exclusively on lengthy interviews while critically selected sample participants (Giorgi, 2009; Moustakas, 2014; Raagas, 2010). Moreover, through the lens of phenomenological research, it stressed out the necessity of treating experiences and behavior as collaborated parts of the single whole (Moustakas, 2014).

Likewise, as a qualitative researcher, gathering of data was done through examining documents, observing behavior or interviewing participants. It was their prerogative to use a certain protocol as an instrument for collecting data but the researchers themselves gather the information. Unlike other research design this does not depend on questionnaire or instruments developed by other researchers (Hatch, 2002). Hence, qualitative design collects various forms of data, like interviews, observations, documents and audiovisual information than simply relying on single data source. After that, review all the data, make sense of it, and synthesize it into categories or themes that cut across all of the data sources (Creswell, 2013).

In like manner, researchers create patterns, categories, and themes following a bottom up by organizing data into increasingly more abstract units of information. Inductively, it illustrates the process of working back and forth between themes and database until such time a comprehensive set of themes were established. And working deductively, researchers look back at their data from the themes if evidences can support each theme or there is a need to gather additional information. By this a deeper understanding of social phenomena and deep comprehension commence in inner experiences and language (Marshall \& Rossman, 2011; Silverman, 2010). Thus, the focus was on learning the meaning of the participant's problem or issue. Meanwhile, during the process emergence was possible. This means that there was no fix plan for research and some or all phases of the process may change or shift after collection of data. The inquirer at the same time reflects about how their role in the study and their personal background, culture and experiences hold potential for shaping their interpretations, such as themes they advance and the meaning they ascribe to the data. Lastly, this involved generating multiple perspective, identifying the many factors involved in a situation and formulate holistic picture that emerges (Brown \& Creswell, 1992; Creswell, 2013; Hatch, 2002; Marshall \& Rossman, 2011).

In addition, phenomenological study highlights the prominent questions of everyday experiences deemed to be significant sociological or psychological phenomena of particular group. Also, it concentrated in describing the incidents from the perspectives of these people have experienced the situation (Raagas, 2010). To state for a fact, bracketing was essential in a phenomenological study, in this sense the researcher must identify first what he wanted to discover. The essence of bracketing made the researcher aware of the possibility that their values, beliefs and decisions may influence the setting of the research (Porter, 2011). Therefore, in describing the phenomenon of the participants, I made use of an analogy of my approach as it was suited to the same this would mean making comparisons, finding similarities and correlations of the various poetry so that common theme about the subject might be extracted. I have interpreted the cause, contributed and related to the phenomenon counter check with my personal experiences and to the subject itself (Ariola, 2013).

To recapitulate, this involved interviews and discussions with Kagan participants in areas of Tagum City, 
Davao del Norte. As it has been said the concern was on human experiences which was conducted in the natural settings. The information was processed through observed phenomenon. I have used phenomenology because basically it focused on the people's lived experiences. As mentioned and part of the study, I was careful and observant at all times, being conscientious of any obtainable beliefs on the study. I made sure that I captured fully the participants' experiences as they have freely discussed to me during the interview. I extensively and tightly aware on the phenomenon that the participants had given during the interview although, I made clear to myself to set aside my own views and personal biases and experiences by completely identify its real fundamental nature.

In qualitative research, sources are not solely limited on printed materials but profoundly interviews and discussions, personal observations and valid documents. In conducting this study, I utilized strategies and techniques such as substantial interviews using video recorder, take down notes and focus group discussion. Likewise, I included observing the emotional details of the participants to generate a significant and holistic output a kind of study.

Research Participants - The selected participants were coming from the community of Kagan of Tagum City, Davao del Norte. The selection and participation of informants for focus group discussion ranges from six to ten individuals and which were heterogeneous yet they met the requirements to qualify as respondents for the study. However lesser than six participants would affect the potential information and wisdom whereas a large a size would have made hard for the researcher to manage and participants to cooperate in the study. In the application of focus group, two important questions were needed to consider: (a) whether to have homogeneous a sample participants/respondents coming from the same group or heterogeneous a sample participants/respondents coming from diverse socioeconomic background; (b) how many groups to have (Dornyei, 2010).

To guarantee that the research participants are with the valuable knowledge and experiences and to be certain that they are all of mature, selected Kagan members who were ages 21 years old and above. They comprised the Kagan who served as the informants/respondents of this study. To light things, a purposive sampling of five to twenty-five individuals was used in the conduct of phenomenological study. The number of participants was 14 Kagan individuals and divided into two each group composing of 7 Kagans. Thus, the study followed the prescriptive number of participants (Raagas, 2010). Furthermore, the standard practice was to run a number of focus groups in any research. By this, way we can diminish any idiosyncratic results that occur because of some unexpected internal or external factor that influence the dynamics of a group. Therefore, in order to achieve adequate breadth and depth of information often recommended that a research should involve two groups as a minimum. The two groups of Kagan respondents should be knowledgeable on their cultural practices specifically to their poetry since the focal point of this study is about Literary Analysis under Archetypal Approach. The sample was, I believed fairly typical of participants in groupings of Kagan in their community (Dornyei, 2010).

Specifically, and in light to the included research participants, inclusion criteria were clearly established before the selection. With this, Childress, Meslin and Shapiro (2005) defined inclusion criteria as the thorough descriptions of the research population. The research participants have the attributes that helped to make possible to accomplish the purpose of the research. Significantly, inclusion criteria are the characteristics of the prospective subjects that they have to possess if to be included in the research participants such as age, gender, race, ethnicity and etc. Further, as part of the inclusion criteria of this study were: (i) participants were pure blooded Kagan and resident of the Tagum City, Davao del Norte (ii) most of them were older Kagan to ensure that they have vital experiences that will serve the study (iii) they were knowledgeable about the tribe and most of the general practices of Kagan such as but not limited to: Giving Birth, Christening, Birthday Celebration, Wedding, Funeral Ceremonies, Religious Practices and Special Gatherings or Ceremonies are observed in their culture (iv) they have a good background about the Kagan literature especially in Kagan poems (v) they were coming from the crossed-section of the society like professional, non-professional, commoner, middle class, 
early adult, elderly and youth to observe richness of the data collected.

As such, 14 informants were included in the research. These were divided into two, seven participated in the in-depth interview and the other half participated during focus group discussion. Since the identified number of respondents involved in my study is supported by an author. As a recap, it dictates there should at least six participants for the in-depth interview and focus group discussion in a qualitative study. Wherefore, my research participants were enough for the saturation point in order to elicit themes (Mason, 2010).

Data Collection - To get the important data several, processes were undertaken. At first, I thought of a topic which was feasible and meaningful. Having successfully came up with the topic to delve with, I then discussed it with my research adviser to clarify and be guided on how to conduct. Thus, preliminary activities and proper planning was done regarding the conduct of the study. Afterwards, I sent letter asking for permission to the City Cultural Communities Affairs Division (CCCAD) of LGU Tagum thru the National Commission of Indigenous People (NCIP). As suggested by the said office in order to expedite the process and conform with the suggestion of the internal validator, to have a ready copy of poems rather than directly getting these to them, I downloaded available Kagan poems. These collections of poems come from a credible source from a joint study of Bureau of Elementary Education and Institute of National Language of the Ministry of Education, Culture and Sports Manila, Philippines. These were validated by the cultural masters of Kagan and the City Cultural Communities Affairs Division. The sample poems were presented and discussed comprehensively with the research participants through the help of a gatekeeper. In the identification of my corpora, it does not suggests that these belong to a certain category of poetry but as long as a Kagan poem. It was ascertained by the informants that these have a cultural significance. And so, proper decorum and protocol were observed in the gathering of data and guided by the key points in the ethical consideration.

Significantly, a gatekeeper was vital to guide the researcher the proper way of interviewing and conversing with the informants likewise to inform about his responsibilities as an interviewer. A gatekeeper was an indigenous member of the community who has either formal or informal influence with the culture. He/she has the access to the site and allows or permits the research to be done. The Gatekeeper in my study is a well versed in the native language of the Kagan to make the informants feel free to converse and express their ideas and thoughts about the questions that had been asked (Backhouse, 2012; Creswell, 2013). Observation gave the researcher a firsthand experience with the participants. He has recorded the information gathered during the interview and discussion. The unusual aspects can be noticed during observation which may contribute to the additional input in the research. Hence, it is useful in exploring topics that may be uncomfortable for participants to discuss (Biklen \& Bogdan, 1992).

Interview is integral and contributes significantly in so many ways especially in the gathering of data. The in-depth interview and focus group discussion were used in this study. These are useful when participants cannot be directly observed. The participants in this manner provide historical information. More so, the researcher has the control over the line of questioning (Creswell, 2013). Document was one of the sources of information of the research. It enabled the researcher to obtain the language and words of participants. This can be accessed at a convenient time to the researcher. It is an obtrusive source of information. Documents validate the participants' responses. Since these are written evidences, these save the researcher's time and achieves credibility of the research output. Examples of these are public or private documents, minutes of meeting, newspaper, journals, diaries or letters (Merriam, 1998).

Audio-visual materials were devices used during the conduct of study such as photographs, videotapes, art objects, computer messages, sound and film. These may be an unobtrusive method of collecting data. Likewise these provide an opportunity for participants to directly share their reality. These materials creatively capture attention visually such as the emotion and feeling of the participants (Bogdan \& Biklen, 1992; Creswell, 2013; Merriam, 1998).

To reiterate, before the conduct of data collection I wrote a consent letter to the National Commission of 
Indigenous People thru City Cultural Communities Affairs Division about my intention to conduct the study. I personally appeared to that office and asked permission. The intention was to formally informed the tribal chieftain of Kagan about my desire to conduct a study of the said tribe and their place at the same time request for potential informants for interview and discussion. However, as a researcher who was guided by a protocol I ensured the confidentiality and agreements between the respondents and the researchers. Thereafter, the gathered documents have paved the way in the efficient and effective literary analysis of the selected Kagan poems. Given the recorded and captured data every instrument has been transcribed verbatimly to produce a high quality of accuracy during the data analysis.

Further, to successfully collected data from the informants an in-depth interview and focus group discussion were utilized among the Kagan tribesmen. Hereafter, data collected underwent series of treatment and an interpretation was made. This was validated by an expert. To make the gray area clear these were presented in the succeeding chapters. The collected data were transcribed, presented and discussed but treated as confidentially. These were analyzed, explored, documented and treated as what was being required of the study. Thus, related to studies and literature were presented to support and validate the ideas extracted. Wherefore, the gathered information and observations during the interview and discussions among the Kagan people were the basis for the analysis of the literary features. Absolutely, to ensure the authenticity and veracity of Kagan diction and language; I asked for assistance coming from Kagan who was proficient both the Kagan and the English language.

Data Analysis - Presented herewith was the systematic retrieved document and responses which were treated in the data analysis. Application of audio and video recorder was a tool to systematically transcribed raw data into written expression. Archetypal approach was vital in deducing the archetypes and general themes of the study. As provided by Biklen (2012), systematic qualitative analysis can be done through working, organizing, and breaking it into managing, synthesizing, searching for patterns, and elaborating significant thoughts from not so important. Therefore, there was extensive and in-depth analysis of raw data subject for logical meaning of factions. Indispensably, after the CCCAD and cultural masters of Kagan approved the downloaded poems, symbols were identified. And regarding with the determined symbols from the corpora these were based from archetypal approach that symbols were common to the human collective unconscious or universally accepted. Likewise, these symbols were presented to the informants if these were symbolically significant. And they have affirmed to it. Furthermore, the translation of these Kagan poems to English language was ready available from the electronic copy and considered to be universally accepted. Also, the informants validated the translation that this was the correct English translation. Again, analysis made, table presentation and information were validated and confirmed by the cultural masters of Kagan and credible individuals, who were knowledgeable to the said topic.

In the table presented under chapter three implored were the idea of Ferdinand de Saussure (1966) about semiotics that dealt with the signs and the association of it with objects and meaning. Sign is composed of a signifier and signified. Signifier stands for the sound associated with or image of something while signified is the idea or concept of the thing and sign is the combination of signifier and signified forming a meaningful unit. The basis of analysis of this research study was the Comparative Analysis using Archetypes of the works of T.S. Eliot and Nathanael West by Linnea Nelson (1974). It was an illustration of the reworkings of the archetypes used by the two authors. To magnify for a fact, this research stressed that it was an analysis which centers across the literary features under Archetypal Criticism. In connection, the central intent of data analysis was to make sense out of text and image data such as segmenting and taking apart the data as well as putting it back together. Guest, McQueen and Namey, (2012) suggested that in the analysis of data the "winnow" technique for the data should be applied a process of focusing on some of the data and disregarding other parts. The impact was to aggregate data into a small number of themes, like five to seven themes (Creswell, 2013).

Important to magnify the steps in data analysis as suggested by Creswell (2013) which was presented in linear, hierarchical approach building from the bottom to the top. (i) organize and prepare the data for analysis; 
(ii) read or look at all the data; (iii) start coding all of the data; (iv) generate a description of the setting or people as well as categories or themes for analysis; (v) making an interpretation in qualitative research.

First, the researcher organized and prepared the data for analysis. The process of transcribing, interviews, scanning material, encoding of field notes, sorting and arranging the data into different types depending on the sources of information. Afterwards, read or looked at all the data. This provided an overall sense of the information and an opportunity to reflect on its general meaning. It developed a wide view of participants saying, tone of the ideas, overall depth, credibility and importance of the information. Next, researcher started coding all of the data. At this point coding was done through organizing collected data by bracketing chunks and writing a word representing a category in the margins. To elaborate, it involved taking data or pictures gathered and segmenting these sentences or paragraphs into categories. Hereafter, label those categories using a term which was based in the actual language of the participant called as in vivo term (Rallis \& Rossman, 2012). Henceforward, the coding process was used to generate a description of the setting or people as well as categories or themes for analysis. The process under description gave elaborate and detailed information about the people, places or events in a setting. By this, codes can be generated which gave a small number of themes or categories and these themes appeared as major findings in qualitative studies. However, provided they should display multiple perspectives from individual while supported by quotations and evidences. Hence, identification of themes built additional layers of complex analysis and shaped into a general description under phenomenology (Creswell, 2013).

Finally, data analysis made an interpretation in qualitative research of the findings or results. The researcher has now captured the essence of lessons learned during the conduct of the study. These lessons could be the researcher's personal interpretation or can also be the meaning learned from comparison of the findings with information gleaned from literature or theories. With that, past studies and researches conform past information or diverge from it. Notwithstanding to raise questions overlooked by the researcher but evident in the data and analysis. Furthermore, qualitative researcher used theoretical lens can provide interpretation that call for action agendas and change (Guba \& Lincoln, 2012; Wolcott, 1994). In connection, qualitative content analysis was a collection of sample consists of purposely selected instance which reflected the research ancestors being studied. In this regard, all prejudgment and experiences of the researcher should be set aside. This was done to achieve equilibrium between subjectivity and objectivity. This gave emphasis to unique themes that illustrated the range of the meaning from the phenomenon rather than a sample of numerical representation. In qualitative content analysis magnify the characteristic of language in communication relevant to content or contextual meaning of the text. More so, the result provided and documented were all coming from the answer of informants during the interview and discussion which give light to ambiguity of this research (Budd, 2013).

Precisely, triangulation was used to put validity of the study. Under triangulation various methods has been used such as individual interview and focus group discussion and personal observation these composed the data collection strategies. Through focus groups and individual interviews were both have common methodological shortcomings but their distinct characteristics also resulted in individual strengths. Further, it provided sources of that validated and counterchecked the findings of the interview and triangulation strengthens a study by combining methods (Patton, 2012). Moreover, triangulation was a method for validation or verification and generally used as a technique to ensure that an account is rich, comprehensive and well developed. The different data sources of information by examining evidence from the sources and using it to build a coherent justification for themes. Research question number one and two were used for triangulation (Crabtree, 2014).

Focus Group Participant Identification. It was guaranteed that the data gathered or the knowledge elicited from the participants was only common to the people attended the interview and no information leaked outside the circle of the group. The participants as well, were reminded to keep the information discussed confidential.

Observation. Before the conduct of research interview the places where the data gathering had taken place were first prepared. Part of its preparation was the putting of prior notices in the area such as signage in the 
participants' houses or where the interview conducted. Included in the notification were the exact time, location and event. This was done to inform the public of the future happenings and avoid destruction during the interview.

Permission from Organization/Location. Before to start the data collection I wrote a consent letter to the National Commission of Indigenous People thru the City Cultural Communities Affairs Division of Tagum City about my intention to conduct the study. I had personally appeared to that office and asked permission. Likewise, I informed the concern Barangay Official about the endeavor. The intention was to formally inform the tribal chieftain of Kagan about my desire to conduct a study of the said tribe and their place at the same time requested for potential informants for interview and discussion. However, as a researcher who was guided by a protocol I ensured the confidentiality and agreements between the respondents and the researchers.

Anonymity. Confidentiality of the identities of the research participants were the paramount consideration of the study. However, as per requested by the informants themselves that their identities should not be hidden and explicitly revealed their names.

\section{Results}

In view of the research problem, the conducted data gathering paved to the development of substantial information which were relevant to this study. Of the two sources of data in-depth interview and focus group discussion both were carefully tape-recorded and followed the protocol in the ethical consideration. The responses were cautiously transcribed and assessed thoroughly through the process of categorization of themes. Kagan participants are divided into two each group has seven members, whom all met the research inclusion criteria as stated in chapter three. In answering the first qualitative research question, the researcher himself downloaded an existing Kagan poems. This is made for ready references of the informants to give their symbolic interpretation. Thereafter, researcher interpolated symbolisms on how informants gave their cultural significance and universal meaning. Another source of information was the gathered data during the interview and focus group discussion from which significant themes were drawn. Likewise, online data, books and Kagan vocabularies and conversations were used as one of the bases of this study.

It was clear, that my research participants were people coming from the Kagan tribe who met the inclusion criteria. As shown in Table 1, there are 14 Kagan who were respondents in the study, divided into two seven for in-depth interview and seven for focus group discussion, and of the 14 of them, four were males and ten were females. All belong to the Kagan tribe.

In-depth interview. There were seven key informants in this group, six women and one man who were all living in Tagum City, Davao del Norte. As guided by the principle of confidentiality and ethical consideration, each participant under in-depth interview was assigned a pseudonym in the presentation of results and transcription of the raw data, as per suggested by Bernal (2014). The assignment of which was made according to their distinct physical characteristics and attitudes as portray during the interview sessions. To illustrate, Talkie was the name given to the participant with a talkative and accommodating attitude. Maester was named to the participant who was the leader of the tribe and knew a lot about their culture. Elderly was attributed to the eldest woman in the interview. On the other hand, the sophisticated and cheerful participant was named Sophie. While, Guru was named after being matured by experiences making her an expert in Kagan practices. And Servant was named to the participant who was a public servant in the government. Lastly, Protectress was named to the informant who was a cultural master of the tribe.

Focus group discussion. Likewise, in this grouping pseudonyms were also assigned to each participant. Tita was assigned to this woman because she was not that really old but somewhat with a character of being good and caring aunt. Healer was also given to this old man who was very knowledgeable about the traditional medicine and healing in the Kagan tribe. Also, Imam was named to this spiritual leader of the tribe and who presided religious exercises inside the mosque. Chuabbz or short for chubby was given to her because of the physical built 
up she has. While, Mamma was named to this woman who has a motherly attitude and soft spoken person and Ernest was the name of this next informant who was characterized of being serious. Shyness was given to this aged woman who has an introvert personality.

\section{Table 1}

Participants' Information

\begin{tabular}{lllcc} 
Name & Age & Gender & Ethnicity & Study Group \\
\hline 1. Talkie & 59 & Female & Kagan & IDI \\
2. Maester & 65 & Male & Kagan & IDI \\
3. Elderly & 86 & Female & Kagan & IDI \\
4. Sophie & 28 & Female & Kagan & IDI \\
5. Guru & 55 & Female & Kagan & IDI \\
6. Servant & 34 & Female & Kagan & IDI \\
7. Protectress & 67 & Female & Kagan & IDI \\
8. Tita & 57 & Female & Kagan & FGD \\
9. Healer & 76 & Male & Kagan & FGD \\
10. Imam & 82 & Male & Kagan & FGD \\
11. Chuabbz & 68 & Female & Kagan & FGD \\
12. Mamma & 67 & Female & Kagan & FGD \\
13. Earnest & 66 & Male & Kagan & FGD \\
14. Shyness & 71 & Female & Kagan & FGD
\end{tabular}

In the conducted interview and discussion, the same set of research interview guide was used for the two groups. To identify the participants in the research study, the researcher considered the recommendation of tribal chieftain who all fitted the research problem. By means of snow ball sampling method by Woodsong (2011), I was able to obtain respondents through the process of referrals and recommendations made by an expert of the target tribe. The meetings with the research participants were organized by the gatekeeper and facilitated the collection of rich information. Given the fact, that the gatekeeper knew the background of each participant and they trusted each other, this guarantees them to share sensitive and insightful information about the serious topic.

The process of focus group discussion was critical yet interesting and thought provoking. It was a challenge on the part of the interviewer on how to elicit answers better yet a thorough explanation from the participants. But once, the challenge has overcome, rich interaction and sharing of ideas proceeded immediately which made the FGD participants to recall their past experiences which were different from the responses of the other within the group or may it be the same. To add more, this emerged different or the same responses from the in-depth interview.

All-encompassing to that, in-depth interview and focus group discussion were both done and conducted inside a conference room or a suitable place for interview and discussion. In the promulgation of data gathering, I used a tape recorder together with notebook to jot down important information during the IDI and FGD as suggested by Boyce and Neale (2012). Before the conduct of the actual interview and discussion, I asked them if I can take video or pictures while we were having interviews and focus group discussion but they opt not to but instead to record our conversation. In like manner, as suggested in the ethical consideration an informed consent was asked to sign by the informants and secure their approval to audio-tape before each interview. All of the informants have fully understood the consent form and approved the same for one important reason, which was to hide their individual identity and observed carefully.

Categorization of Data - Thereafter the process of individual in-depth interviews and group discussions, the audio-taped conversations were carefully transcribed and analyzed. As a researcher I implored the following steps in the process of data analysis (i) organized and prepared the data for analysis; (ii) read or looked at all the data; (iii) started coding all of the data; (iv) generated a description of the setting or people as well as categories or themes for analysis; (v) made an interpretation in qualitative research. To stress for a fact, coding process was used to generate a description of the setting of people as well as categories of themes for analysis. The lifted themes from the data provided the general picture of the study. Further, data in this chapter were presented in a table. 
To establish categorization of data, identified themes were presented by research question and referred to as major themes. The themes that had emerged from the study were thoroughly discussed to provide a clear description. Opposite side to the major themes in the table were the core ideas from the responses from the participants. In answering the research question number one, I presented in a table form the data. This is shown in Table 2. In which, in the first column was the poems downloaded. Second was the identified Archetypal symbolism, followed by the Kagan interpretation or meaning for each symbol. Lastly, was to cross-reference the symbolism to other culture or literature. As adopted from the existing study, the researcher applied the format of analysis by Nelson (1974) which was illustrated in a narrative form.

The second way of presenting the data was displayed as presented in Table 3 and 4, herein presented the emerging essential themes in first column with the core ideas to its opposite side. The method of presenting the data in a table form was patterned after the study of Amparo (2011) which utilized the three classifications. First, classification was general which means at least 50 percent of the participants mentioned the item in their response during interview or focus group discussion; typical which means 25 to 49 percent mentioned the item and variant which means less than 25 percent mentioned the item. To illustrate categorization of data, themes extracted through the research question were referred as the major themes. Next to the major themes in the table were the core ideas from the responses from the participants. Further, another column was included in the table showing the frequency of the responses which became the basis for the classification as mentioned general, typical and variant. The last thing was the drawing of conclusion and verification. According to Miles (1994) in this step preliminary and patterns about the findings are developed.

As it was clearly mentioned in the trustworthiness of this research, considered key points suggested by Lincoln and Guba (2012) which were the credibility, dependability, transferability, and confirmability. In order to attain credibility in my study, member checking and peer debriefing were conducted in connection to the triangulation method. To serve the above-mentioned activity, after the transcription of the proceedings in the interview and group discussion copy of the transcript was given to the participants for the purpose of double checking and accuracy of the output. As far as this, informants have had agreed and no negative feedback of the transcribed proceedings. With this so, respondents all signed the verification form.

In view of peer debriefing, assistance from the research adviser, research experts, classmate and other credible professionals in the categorization of the emergent themes and categories was consulted to validate the foregoing analysis. Through the help of debriefing this cleared out the gray areas of the study and further enhanced the diction and vocabulary used to describe the themes and categories. As per observation during and after the data gathering, informants have given their full knowledge and significant experiences regarding the research questions. And so, theme saturation was achieved, like how Woodsong (2011) described to it. Most importantly, triangulation was realized by its twofold sources of information which were review of related literature, key informants and the FGD this was proposed by Creswell and Miller (2000). Exactly, dependability and confirmability were met through the suggestion of Carcary (2015) by applying audit trail. This was applied to give way the research panel verify the researcher's assumption, conjectures and interpretations. On the other hand, transferability was stressed out by claiming from the start and stated in the limitations of the study, that the end result has not directly generalized other poem interpretations and analysis since this was solely coming from the informant's experiences and perceptions. Thus, this only covers the poems at hand and to the place where it was conducted. Likewise, Grempes (2014) one said that if credibility, confirmability and dependability were implored in a qualitative inquiry then transferability was in like manner included.

\subsection{Research Question No. 1: What are the literary features of the Kagan Poetry using Archetypal Approach?}

Oral tradition like poetry as a product was enigmatic in nature. It was the reflection of Kagan's cultural and literary heritage. For this reason, during the analysis of Kagan poems using Archetypal criticism it was found out that these met the standards of the aforementioned approach such as universal meaning of a certain symbol. This means that symbolisms present were culturally accepted across different literature and references. 
Table 2

Archetypal Analysis of Selected Kagan Poems

$\begin{array}{llll}\text { Poems } & \text { Signifier } & \text { Signified Interpretation }\end{array}$

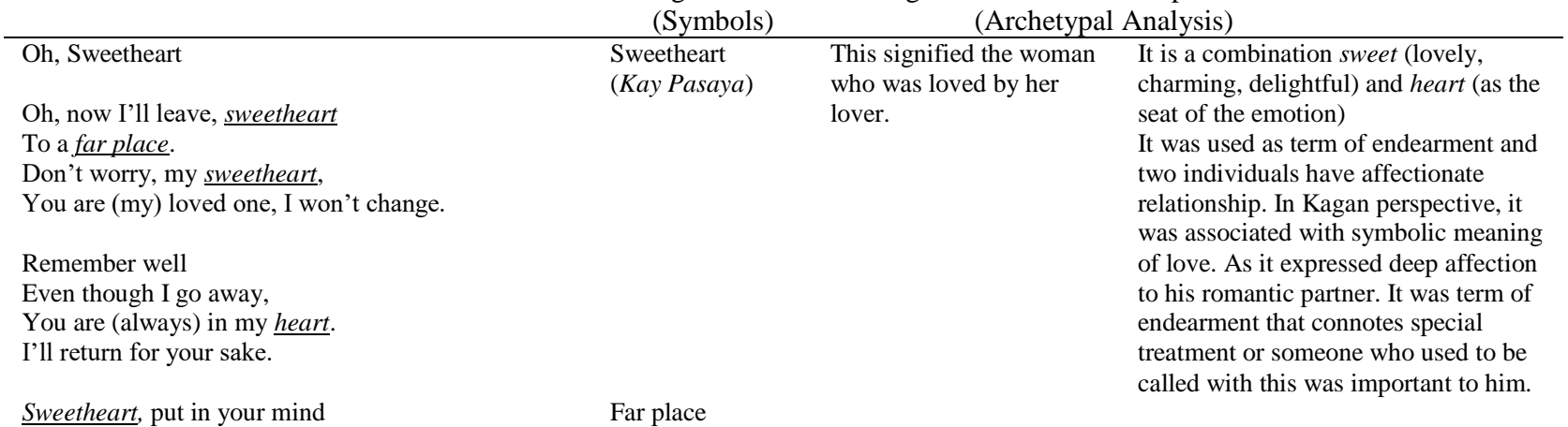

That you are the only one I love. (Mawat na

Wait for my return, sweetheart. $\quad$ banwa)

A place where someone has something to work on and in the contrary it may be a journey to a someplace. The distance between to lovers.

After I finish my work,

I'll return for your sake.

Know that you are the only

Whom my heart is attached to.

It signifies journey or literally a far work place or unexpected circumstances that hinder something.

Heart

(Dumdum

ko/pangatayan)

Iyan kaw sang dumdum ko

Magabarik ako gabap kanmo.

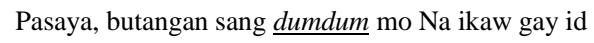
yang pasaya .

Pagtagad pasaya nang pagbarik ko.

Na daw apakawinan ko.

Nang pagkata' ng gawubuk ko,

Magabárik ako sabap kanno. Ratigami na ikaw gay

id

Yang yokutan ng loy ko.

\section{Marriage}

(Kawin)

$\begin{array}{ll} & \\ \text { Work } & \begin{array}{l}\text { This signified union of } \\ \text { (Gawno opposite sex, } \\ \text { happiness and a new } \\ \text { chapter in their life }\end{array}\end{array}$

It is literally means as a far place such as how other short stories will starts: in a far place and far from the city or civilization.

In Kagan people far place symbolized something which was unreachable or some place that was hard to travel on. In like way, this also stands for a journey that a lover need to conquer before he can be with his lover and live happily for a lifetime. A journey which was full of struggles and circumstances which aim to test someone's capability and moral values.

This stands for emotions, Heart symbolized love.

feelings and love. It was the locus of physical and spiritual being, and represents the central wisdom of feeling as opposed to the head-wisdom of reason (Cooper, $82)$.

The seat of emotions and synonymous with affection.

A celebration of heart for St.

Valentine's Day.

Kagan's analysis about the symbolic representation of heart means as the source of one's love, emotion and feeling. It was the seats of the lover's feeling.

According to Jungian psychologists that this archetype was a powerfully influential entity unto itself, that it has a life of its own, and that its primary historical purposes have nothing to do with love. And that if you want to sustain love, idealism, joy and spontaneity in your marriage, you have to consciously work against a momentum that was literally many thousands of years old.

Something that binds two individuals. This marriage archetype in Kagan means a new chapter to newly bonded individuals (man and woman). It is the union of two people who have a mutual feeling and affection to each other. It also symbolizes happiness. 
In Table 2, the first Kagan poem entitled "O Kay Pasaya" with an English translation of "Oh Sweetheart" talked about the lover's forever commitment of his/her love and affection towards his/her lover that wherever he/she goes the love remains. After the researcher has thoroughly analyzed, the following symbolisms were lifted: "Sweetheart", "Far place", "Heart", "Marriage" and "Work". Throughout the history and across different culture and western nationalities the "sweetheart" symbolized the term of endearment as it was an expression of love towards the romantic partner. Kagan people as well associated this symbol to love like it was connected to a loving word called to a lover. The "far place" symbol as it was used in the poem expresses a journey of the lover, wherein he/she will be separated to his/her lover for some time. In literature this stands for a distance or journey before a reunion will happen between two lovers and comparatively to Kagan sense this refers to unreachable place.

Likewise, this connotes a journey towards achieving something in the pursuit of long lasting love which test the lover's attitude and persistent. The "heart" archetype symbolized as the sit of wisdom for love and affection and the same was to Kagan interpretation as it stands for the central of emotion, feeling and love. As it was presented in the poem this was the keep of his/her love for the special person he/she referring to. Marry was the exact word mentioned in the piece but this directly refers to the "marriage" symbol which across different cultures agreed to the symbolism it represented, as a ceremonial activity that symbolically binds two individuals who have mutual feelings and affection towards each other. The same was given by the Kagan people and according to them this brings happiness and contentment. In the fourth verse the "work" archetype was stated as "After I finish my work," the hero or lover undertakes some long journey during which he or she must perform impossible tasks, battle with monsters, solve unanswerable riddles, and overcome insurmountable obstacles in order to get back his/her loved one.

\section{Table 2.1}

Archetypal Analysis of Selected Kagan Poems

\begin{tabular}{|c|c|c|c|}
\hline Poems & $\begin{array}{l}\text { Signifier } \\
\text { (Symbols) }\end{array}$ & (Archetypal Analysis) & $\begin{array}{l}\text { nterpretation } \\
\text { Analysis) }\end{array}$ \\
\hline What Shall I Do & \multirow{18}{*}{$\begin{array}{l}\text { Melancholy } \\
\text { (Di-mapaky } \\
\text { ilawng) }\end{array}$} & \multirow{9}{*}{$\begin{array}{l}\text { This signified trying } \\
\text { times and serious } \\
\text { problem faced by } \\
\text { them. }\end{array}$} & \multirow{9}{*}{$\begin{array}{l}\text { Symbolically it was an expression of intense } \\
\text { emotion felt by someone when people and } \\
\text { characters are the opposite end of the spectrum: } \\
\text { They dwell more on the past and are more the } \\
\text { glass half empty types. } \\
\text { According to them melancholy symbolized as } \\
\text { the trying times of the tribe when someone or } \\
\text { the group is/are facing a serious problem. This } \\
\text { may also be an extreme emotional challenge. }\end{array}$} \\
\hline What shall I do & & & \\
\hline Now that you are not (here)? & & & \\
\hline Now that you are in a far place. & & & \\
\hline What shall I do still? & & & \\
\hline Sweetheart, remember well & & & \\
\hline What you said, & & & \\
\hline I am the only one you love. & & & \\
\hline I am the only one you care about. & & & \\
\hline & & \multirow{9}{*}{$\begin{array}{l}\text { It signified someone } \\
\text { who was in loved or } \\
\text { being loved by his/her } \\
\text { lover. }\end{array}$} & The core good for the lover archetype rests in \\
\hline Return (to me), sweetheart. & & & bliss and unity. \\
\hline Let's resume our loving. & & & They perceived the meaning of the world by \\
\hline Let's $\overline{\text { return to our past. }}$. & & & way of being in-love and in happy relationship \\
\hline Let's return to our love. & & & and valued love giving and receive it as well. \\
\hline & & & It does not primarily focus on pure intimacy \\
\hline Sweetheart, oh, sweetheart, & & & and sexuality but highlights commitment and \\
\hline Think about the past days, & & & passion. \\
\hline The learning of our loeve. & & & Magnified the joy of being with someone else \\
\hline
\end{tabular}


Literary poetic tradition: An archetypal analysis of selected Kagan poems

\begin{tabular}{ll}
\hline You are the happiness of my heart. & \\
You are the strength of my body. & Lover \\
(Managta-was)
\end{tabular}

Magaokano ako

Magaokano ako

Adon na wa da kaw? Adon na mawat da

kaw Magaono pa ako?

Pasaya dumduna ng madayaw Yang piyaglawongan . Na ako gayid yang pasaya mo.

Na ako gayid yang akawoyan mo.

Ori da, kay Pagaya I ayanta yang paglinoyay ta.

Barikon ta yang mga kaagi ta.

Barikon ta yang mga pasad ta

Pagaya, O Pagaya, dunduna Yang allaw na yamagi

Na iImo ng paglinoyay ta.

Kasowat kaw ng ginawa ko.

Kusug kaw ng badan ko.

Resume our
loving
(Yang
paglino-yay ta)

(Yang mga kaagi

ta)
This signified reviving the love that was forgotten or love that was being challenged by the time.

It symbolized sweet memories or asking for a second chance.

$\begin{array}{ll}\text { Past days } & \text { This symbolized } \\ \text { (Allaw na } & \text { important events. } \\ \text { yamagi) } & \end{array}$

Learning of our

love

(Ilmo ng

paglino-yay ta)

Happiness of my

heart

(Kasowat kaw ng ginawa ko)

Strength of my
body
(Kusug kaw ng
badan ko)
This signified renewing the special and romantic feelings of a couple.
Signified the very special person to his heart who was his lover.

\section{This stands for} something or someone strength in literal and or people around them.

Physically and emotionally attractive so as to maintain this meaningful attention and experience for them.

The lover archetype in Kagan view symbolized as the one who was in love, inspired, motivated, happy and blissful in feeling and emotional state.

This symbolized the act of regaining ones affectionate feeling or love towards his/her lover.

Directly spoke about recuperating one's challenged relationship before and hoping to renew the romantic feeling to your partner.

This symbolized reminiscing to the past experiences of two related individuals.

It was impliedly saying to renew our sweet memories.

It symbolized past event(s) or memories that occur to someone and significantly valuable to his/her.

It was an important events and occasions that are cherished by both lovers.

It was symbolically suggesting reawakening the couple's intimate relationship or love after a circumstances or tragedy happened.

Symbolically it resembles the root of someone's deep blissful feeling and talks about their renewal of couple's special and romantic feeling to each other.

Happiness in this case was the romantic partner of the persona in the piece. It was he/she the source of the happiness. Someone who make him/her happy in a romantic sense or someone who was an inspiration. who was the source of figurative sense.

\author{
In the archetypal sense it was the source of \\ someone's strength. He/she was the inspiration \\ of the persona in this manner. This does not \\ literally refer to food or supplement, rather \\ his/her lover.
}

In Table 2.1 the second Kagan poem entitled "Magaokano Ako" with an English translation of "What Shall I Do" dealt with the lover's praying to be remembered by his loved one and not to be forgotten. That despite the distance and space may his lover still committed and treasured their promised love for each other. With that, researcher has elicited the following symbolisms: "Melancholy", "Lover", "Resume our loving", "Return our past", "Past days", "Learning of our love", "Happiness of my heart" and "Strength of my body". After thorough analysis, an interpretation of these under archetypal approach was made. "Melancholy", signified trying times and associated to extreme emotional challenge which was an expression of intense emotion felt by someone when in opposite end of the spectrum.

The symbol "Lover" signified for the one who was being loved and the one who love someone, who was considered to be the source of inspiration and motivation which was not solely limited to sexual attraction. In the symbol "Resume our loving" it signified renewing the romantic feeling after was being challenged by time and destiny. In like way, "Return our past" signified for remembering the sweet memories of two individuals and may imply as asking for a second chance. The "Past days" symbol directly symbolized special events which were cherished by both lovers. "Learning of our love" on the other hand signified reawakening of couple's intimate relationship after was challenged by tragic circumstances. The "Happiness of my heart" signified someone who was the source of inspiration and motivation. This pertained to the happiness brought by someone in a most special manner and unexplainable in thoughts and words. Lastly, in the symbol "Strength of my body" 
Sultio, A., \& Gomez, D.

signified in Kagan and archetypal sense as someone who was the root of strength and someone who was an inspiration.

\section{Table 2.2}

\section{Archetypal Analysis of Selected Kagan Poems}

\begin{tabular}{ll}
\multicolumn{1}{c}{ Poems } & $\begin{array}{l}\text { Signifier } \\
\text { (Symbols) }\end{array}$ \\
\hline $\begin{array}{l}\text { People who are in Love } \\
\text { (Yang Otaw Magkaombok) }\end{array}$ & Life \\
& (Kinabuwi)
\end{tabular}

Oh, how sweet life is,

Here in the world,

Especially if your companion is

Your sweetheart.

While you passed through

Feasts/Happy experiences

Of davs and nights

Now you are in trouble

What you are thinking about is

That the world is passing by.

People who are in love

Easily forget

That all things shall

Pass through death.

Otaw Magkaombok

(Donya)

O' kadayaw magpakabuwi

Ani sa donya,

Labi da yang upud mo

Yeng Pasayamo

Nang kiyagiyan da mo

Yang karadyaan ng

Gabi aw allaw

Yakaringaw da kaw na kar iko awon kataposan

Adon na yakalasak da kaw

Sang kasikotan .

Iyan da kaw Nakatadun na yang

Donya labayanan,

Yang otaw magkaobok

Mallug magpakar ingaw

$\mathrm{Na}$ yang kar iko kadi Amagi sang

kamatay.

\author{
Signified Interpretation \\ (Archetypal Analysis) \\ This signified In its most general sense, the symbolism of \\ something which was \\ very special and to be \\ given importance and \\ to be positive in \\ dealing with \\ life was compared to a tree like a life of \\ cosmos: its consistence, growth, proliferation, \\ generative processes. \\ The Kagan associates life to something that \\ we have to cherish, be optimistic in living with \\ and to do something according to being an \\ ethical one.
}

The world represents people, relatives, friends,

This signified as a blessing and a blessing which is only temporary. your lover, a specific person (who means the world to you), your kids, your family, struggles, time and astral traveling experiences.

This directly stands for a blessing and at the same time temporary material thing.

$\begin{array}{ll}\text { Feasts/ } & \text { This signified } \\ \text { Happy } & \text { happiness and } \\ \text { experien-ces } & \text { gratefulness and } \\ \text { (Karad-yaan) } & \text { signals changes. }\end{array}$

To feast was to mark a change, or recognize the significance or a certain time. Feasts fall out of realms of normal eating, and elevated it to something sacred, and symbolic and even mystical. Feasting celebrated the relationship between the physical body and the divine spirit, feasting enhances emotions and brought people together.

According to them feasts and happy experiences literally symbolized happiness and gratefulness. Figuratively, acceptance for new changes or something good has had happened.

Days and Nights The Day signified (Gabi aw allaw) happiness and life while Night signified cessation and death

Day and night symbolized, respectively, the birth of the Sun and its death. With the rising Sun, the day was considered representative of new life, and fresh beginnings, possibilities, hopes, and opportunities. It also symbolized the active, masculine principle and the rise of consciousness. Afterward, as the sun starts setting, the day begins to give way to the night with its all-enveloping darkness. As the end of the day, the Night symbolized death, which means ending of life. The darkness of Night also associates it with secrets and dark potentialities.

This stands for chaos, misery, lack of discipline and challenges.

The trouble in the metaphysical aspect such as: calamity, difficulty, disaster, the sure result of wrong thinking. All economic, social, and personal trouble can be traced back to selfishness of the sense man.

Symbolically suggested for momentary, transient and ephemeral.

Trouble (Yakala-sak) It signified an ending for everything and freedom from problems.
The world was passing by symbolically means that everything was temporary here in the physical world.

The symbolism of death can be seen in multiple symbols such as but not limited to: skeleton, snarling dog, gravestones, cemetery, blackness and etc. It was not completely about physical death. It was about observation of it in others; our conceptions of it gained from our culture, and our impressions arising from seeing dead animals, rotting corpses; the feelings that generate around our experiences and thoughts of it; our attempts to deal with 
our ageing and approach to death; social violence.

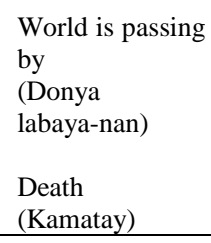

Death archetype in Kagan symbolizes as the end of everything for someone's chances. However, this stands for freedom from the material world or from the problems and challenges from the living.

In Table 2.2, the third Kagan poem entitled "Yang Otaw Magkaombok" with an English translation of "People who are in love" talked about a couple who were deeply in love to each other and were so overwhelmed with their passionate feelings without noticing that time has passed and everything will come to an end. That time was inevitable as to death is unavoidable. After an analysis has been made the following symbols were lifted: "Life", "World", "Feast/Happy experiences", "Days and Nights", "Trouble", "Worlds is passing by" and "Death". The "Life" symbol in a general sense it is compared to a life of cosmos and because of its growth and changes every stage of which should be cherished as it is characterized by the Kagan people.

While the "World" archetype does not directly pertained to the physical world but to the persons who are really dear to you, which likewise you considered as blessings. The "Feasts/Happy experiences" symbolized happiness and celebration which will result to new changes and signals that something would happen. On one hand, "Days and Nights" in general reference these symbolized new beginning and an end. These symbolized birth and death respectively. And "Trouble" symbolized across literature and cultures something that bothers someone may it be caused by chaos, calamity and social, economic and personal trouble. "World is passing by" symbolized temporariness and momentary.

\section{Table 2.3}

\section{Archetypal Analysis of Selected Kagan Poems}

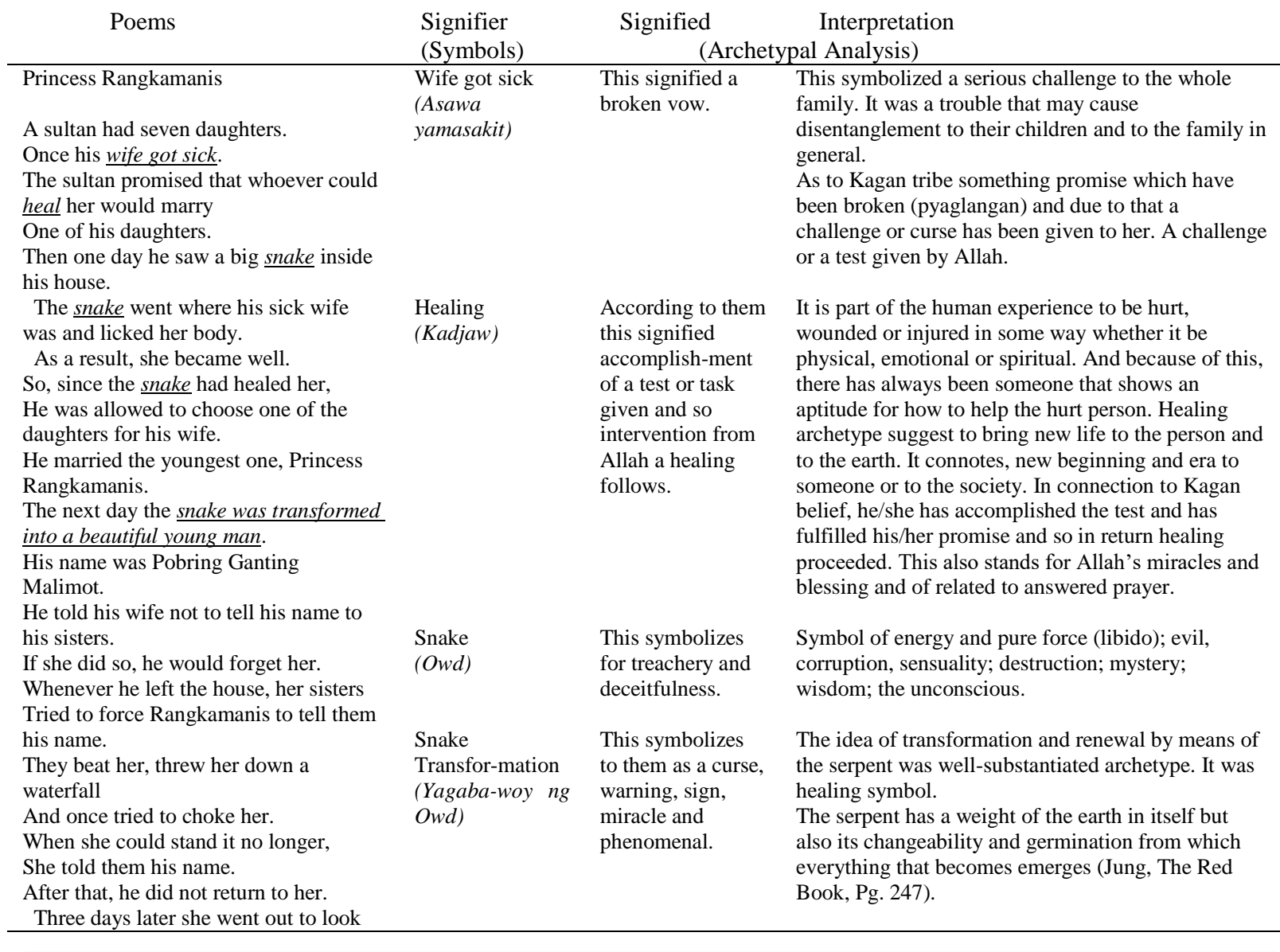


for him.

She took with her a ring and a

handkerchief he had a given her.

As she walked she met some fierce tigers,

Then lions and then elephants.

Each time she showed them the ring and the handkerchief

And told them whom she was looking for,

And they did her no harm.

After some time she arrived at a big cliff.

A wild chicken, a kingfisher and then a hawk each helped

Her get to the garden at the top

of a cliff,

Where her husband lived.

She became an old woman so her

husband could not recognize her,

And she asked if she could be his

servant.

After three months she made bread,

And she put the ring inside the loaf of

bread.

Then she was transformed to a young princess again.

When her husband found the ring,

He realized who his new servant was.

He asked forgiveness for making her his

slave,

And they were both happy.

\section{Putri Rangkamanis}

Awn sultan na awn anak na pito ka kawbayan.

Sangalaw yamasakit yang kanan asawa.

Yang sultan ya pasad na kung sino man yang amakabong o kadjaw sang kanan asawa apakawin nan yani sang kanan anak.

Awn sambok na alaw yakita silan ng od sang sod ng kanilan bay.

Yang od yadog adto sang kanan asawa aw idilaan yang intero lawas yang resulta yamadayaw yang kanan asawa sabap sidto.

e-atagan nan inyan ng kapatot na mapili sang kanan mga anak na ama-inang nan ng asawa.

Ipakawinan nan yang kimod $g$ anak na ipanganan ng Prinsesa Rangkamanis.

Sang yasunod na alaw, yang od yama-inang ng gwapo na usog. Yang kanan pangan kay Pobring Ganting Malimot.

Ilawngan nan yang kanan asawa na $\underline{d i}$ mapakay ilawng o di a-umbad yang kanan pangan adto sang mga lumon ng kawbayan.

Sabad kung alawng nan inyan, amaka pingan yan kang Rangkamanis.

Sang timpo na mapanaw da.

Yan sang kanilan bay yang mga lumon nan piga pugos si Rangkamanis na a-umbad yang kanan pangan. Pya pasakitan nilan yani aw piga dami ng tubig.

Aw piga tigo pa nilan alaw na dida nan kaya yang pag dawg-dawg kanan aw yamalawng nan yang pangan ng kanan bana.

Pagkabus sinyan wada yan bariki. Yalabay yang tulong ka alaw, ipanginaw

It symbolized metamorphosis.

Secret in Kagan, symbolized as strength, a unique Secret quality and (Di mapakay weakness. ilawng)

Handker-chief (Musa)

Tigers, Lions and Elepha-nts (Tigre, Lion \& Elepante)

\section{Cliff}

(Pangpang)

Wild Chicken, King-fisher and Hawk

(Yas na manok,

Bakaka

Mandagit)

Old woman

(Buyag)
This played a vital role in a ritual healing or ceremonial event. Likewise stands for approval.

Tiger in Kagan symbolized courage and something to be feared with.

Lion in Kagan stands for bravery and courage and also something to be feared with. The elephant symbolized to them as happiness, prosperity and courage.

This symbolized danger, an obstacle, death and somehow connected to purgatorio.

Wild chicken signified being an introvert and mystic.

\section{Kingfisher} signified fear

Hawk signified vision and threat.

It signified someone who is with high degree of wisdom and respected one. supremacy, high
This archetype symbolized weakness, downfall, destruction, a plan, a weapon or an undercover.

Handkerchief symbolized different things to different characters, it symbolizes love if given by someone. It stands for faith, fidelity, chastity and marital fidelity. It implicitly suggests a guarantee of virginity as well as fidelity (Othello by W. Shakespeare).

Tiger symbolized competitiveness, self-confidence, bravery, willpower, courage and personal strength

Lion was a very diverse symbol. Its most common traits are; majesty, strength, courage, justice and military might.

Elephants have a positive symbolic meaning all over the world and are considered a symbol of good luck, power, success wisdom and experience.

The cliff archetype signified obstacles, troubles, new opportunities, a great possibilities, strength, vitality of life, a new beginnings and tribulations, achievement in life, a barrier to harmony.

The chicken archetype symbolized parental and spiritual love in the literature of the West. An example in Mathew 23:37, for example, Jesus invokes the symbol of a mother hen and her chicks to express the relationship he desired to have with the Hebrew people when he says, "O, Jerusalem.. how often would I have gathered thy children together, even as a hen gathered her chickens under her wings." The hen symbolized ideal maternal love and Christian love: she was self-sacrificing, nurturing, protective, and comforting. The wild chicken in Kagan symbolizes introversion and of associated with pagan people and also expresses mystic.

In the biblical sense, Kingfisher archetype was said to be the first bird to fly from Noah's ark after the deluge, supposedly received the orange of the setting sun on its breast and the blue of the sky on its back. It was considered a symbol of peace, promising prosperity and love. The kingfisher symbolized fear, it signals time setting and of with a character of being a predator.

The hawk symbolized the ability to use intuition and higher vision in order to complete tasks or make important decisions and characterized as being supreme.

The archetypal of an old woman signified mysteries of life, death, transformation; the female principle associated with the moon. This represent to Kagan like its universal meaning carries a persona of having wisdom and highly respected.

Bread became the symbol of the supreme gift from God to humankind - eternal life, the body of Christ in the Eucharist. It also stands for resurrection. Like in Kagan this stands for a source of strength and prowess.

This kind of archetype connotes transformation of someone's character in a deeper sense. It signified a new beginning or life. 


\begin{tabular}{|c|c|c|}
\hline $\begin{array}{l}\text { nan yang kanan bana. } \\
\text { Sang kanan pag panaw aw pag } \\
\text { panganap piga dada nan yang e-atag ng } \\
\text { kanan bana na sing-sing aw musa. } \\
\text { Sang kanan pag panaw yama sugat nan } \\
\text { yang mangkaysog na tigre, lion aw } \\
\text { elepante sang oras na apakita nan } \\
\text { kanilan yang sing-sing aw musa aw } \\
\text { alawng kung sino yang kanan piga } \\
\text { panganap di yan a ilabutan aw } \\
\text { apasakitan. } \\
\text { Sang ka dugay ng kanan pag dalag } \\
\text { yadatong yan sa pangpang. } \\
\text { Yas na manok, bakaka aw } \text { mandagit aw } \\
\text { uman isa kanilan itabangan nilan si } \\
\text { Rangkamanis na madatong sa harden } \\
\text { adto sa babaw ng pangpang, adto pag } \\
\text { uya yang kanan bana. } \\
\text { Yama-inang yan na buyag agaw di yan } \\
\text { pagkilawn ng kanan bana aw yan ya } \\
\text { angyo na a-inangon dagaid yan na alang. } \\
\text { Yamalabay yang tulong ka buwan yaga } \\
\text { luto yan ng sambok na pan, aw } \\
\text { ipalamanan nan ng sing-sing yang sod } \\
\text { ng pan. } \\
\text { Pagkabus sinyan yabarik } \\
\text { Yan sang sambok na mapawa aw daga } \\
\text { na prisesa. } \\
\text { Sang pagkakita ng kanan bana sang } \\
\text { sing-sing adto panan ikatigaman kung } \\
\text { sino yang kanan alang. } \\
\text { Aw yan yapangayo payon ng } \\
\text { kaamponan sang kanan yama inang na } \\
\text { e-inang nan alang. } \\
\text { Aw pagkabus sidto ya uya yan na } \\
\text { malipayon. }\end{array}$ & $\begin{array}{l}\text { Bread } \\
\text { (Pan) } \\
\\
\text { Transfo-rmation } \\
\text { (Yama-umar) }\end{array}$ & $\begin{array}{l}\text { Bread } \\
\text { accordingly, } \\
\text { symbolized a } \\
\text { source of strength } \\
\text { and power. } \\
\text { This archetype } \\
\text { symbolized a help } \\
\text { or a blessing from } \\
\text { Allah. It is } \\
\text { connected to } \\
\text { changes. }\end{array}$ \\
\hline
\end{tabular}

In Table 2.3, the fourth Kagan poem entitled "Putri Rangkamanis" with an English translation of "Princess Rangkamanis" was written in a narrative poem form, narrates the story of a princess named Rangkamanis who became the trophy to someone was healed her mother. She had married the healer whose name was a secret to her sisters, but she has disclosed this which made to forgot her own name and made to separate them from each other. And later on found their ways to meet each other again. After an archetypal criticism has been made the following symbols were lifted: "Wife got sick", "Healing", "Snake", "Snake transformation", "Secret", "Handkerchief", Tigers, Lions and Elephant", "Cliff", Wild chicken, Kingfisher and Hawk", "Old woman", "Bread" and "Transformation". In the case of the symbol "Wife got sick" signified a broken vow and in the interpolation of archetypal analysis it is related to a trouble that may cause problem to the family. It was a curse thrown to her maybe because of her ill character or caused by unfulfilled promise. While "Healing" as an archetype both in Kagan and universally accepted for new life and beginning and blessing. The "Snake" archetype in Jungian interpretation symbolized pure force, evil, corruption, sensuality, destruction, mystery, wisdom, treachery and deceit.

The "Snake transformation" generally in Kagan and universally displayed a symbolism of healing and miracle. "Secret" on the other hand took a symbolism as a weakness, downfall, destruction and unique quality. This secret symbol was related to the secret like the Achilles heel. The "Handkerchief" archetype signified for faith, fidelity, chastity and pureness. While on the one hand, "Tigers, Lions and Elephants", the Tiger signified courage and bravery; Lion symbolized strength, courage and bravery while Elephant signified for prosperity and luck. The "Cliff" symbol represented obstacles, troubles, new opportunity and tribulation. "Wild Chicken, Kingfisher and Hawk" individually these has its own symbolism, the wild chicken though it does not have a gender but in the bible this is characterized as a symbolism of an ideal maternal love and Christian love. The kingfisher symbolized peace, prosperity and love. According to the bible this was the bird to fly from Noah's ark. While, hawk was a symbol of high vision and order. The "Old woman" archetype in Kagan and in other countries this symbolized wisdom and honour. While "Bread" on the contrary, signified source of strength. 
Sultio, A., \& Gomez, D.

Finally, "Transformation" symbolized blessing and a new beginning.

Table 2.4

Archetypal Analysis of Selected Kagan Poems

\begin{tabular}{|c|c|c|c|}
\hline Poems & $\begin{array}{l}\text { Signifier } \\
\text { (Symbols) }\end{array}$ & $\begin{array}{l}\text { Signified } \\
\text { (Archetypal Anal }\end{array}$ & $\begin{array}{l}\text { nterpretation } \\
\text { is) }\end{array}$ \\
\hline $\begin{array}{l}\text { The Three Orphan Siblings } \\
\text { The orphans, two brothers and a sister } \\
\text { Were living with their aunt. } \\
\text { She treated them very badly so after some time they } \\
\text { left. } \\
\text { They walked for several days until they got to a } \\
\text { place } \\
\text { Where they wanted to live. } \\
\text { The oldest one built a hut and they lived there. } \\
\text { A long time after, while the oldest one was working } \\
\text { in the field, } \\
\text { An old man passed by. } \\
\text { He was thirsty and the oldest boy gave him some } \\
\text { water. }\end{array}$ & $\begin{array}{l}\text { Aunt } \\
(B a b o)\end{array}$ & $\begin{array}{l}\text { It signified a second } \\
\text { mother whom sometimes } \\
\text { characterized of being } \\
\text { terrible. }\end{array}$ & $\begin{array}{l}\text { The Aunt possessed a persona of a } \\
\text { terrible mother in this case. It is } \\
\text { associated with the witch, sorceress, } \\
\text { siren, whore, lamia, femme fatale- } \\
\text { associated with sensuality, sexual } \\
\text { orgies, fear, danger, darkness, } \\
\text { dismemberment, emasculation, death; } \\
\text { the unconscious in its terrifying } \\
\text { aspects. } \\
\text { Aunt archetype in Kagan } \\
\text { interpretation symbolized as a second } \\
\text { mother. A second mother who will } \\
\text { take care to her niece or nephew. But } \\
\text { if sometimes characterized of being } \\
\text { terrible. }\end{array}$ \\
\hline
\end{tabular}

When the old man heard they were orphans,

He gave them a ring that would give them

Whatever they asked for.

After some years the oldest boy decided to go to his aunt's house.

Using the magic ring,

He asked for nice clothes and transformation.

In no time at all,

He had beautiful clothes and yellow handkerchief

Which he was to ride upon.

When he got to his aunt's she did not recognize him

He gave her money and told her who he was.

She asked for forgiveness for having treated the orphans so badly.

Then he went to the tomb of his father and mother.

He dug out the bones and asked the ring to let his parents to live again.

He prayed and fanned the bones and they became alive.

They all went to the aunt's house and she asked the parents'

Forgiveness because she had had no compassion with the orphans.

The young man went to get his sister and brother. Then he cleared a piece of land at this side of his aunt's field.

Again he asked this time,

For beautiful house.

Suddenly the house was there.

The whole family and their neighbours were invited in to celebrate

And after that the whole family lived

Together there and were happy.

Yang to ma Maglonon na mga Mimaylo

Yang maglumon na duwa na waday taganak na duwa na usog aw isa ka bobay silan yakiuya gaid sang kanilan babo pero piga dawg-dawg silan agaw sa yapanaw silan sa bay.

Ya palag silan nga pilang ka alaw taman sang

yadatong silan sang sambok na dapit na yamaynang

nilan na nag-uya yang maguwang nilan yaga tukod ng sambok na kub.

Untak aka uyan nilan. Yalambay yang mga alaw,

yang kanilan maguwang yaga gawbok sa uma.

Awn is aka matikadong nay a agi.

Yang matikadong e-uraw da laban e atagan dayon aw ipa inom ng tubig.

Aw ikatigaman ng matikadong na yang maglumon
Old man

(Matikadong)

This signified wisdom and with substantial experiences.

Oldest boy

(Maguwang na

anak na usog)

It signified a second father who assisted him.

Water

(Tubig)

Ring

(Paninsing)

This symbolized armory, a seal in a marriage.

Nice clothes (Madjaw no dagom)
This signified social status and state of living

300 Consortia Academia Publishing (A partner of Network of Professional Researchers and Educators) 
Literary poetic tradition: An archetypal analysis of selected Kagan poems

\begin{tabular}{|c|c|c|c|}
\hline $\begin{array}{l}\text { waday taganak. } \\
\text { E-atagan nan silan ng sambok na paninsing na } \\
\text { matabang aw ma atag kanilan kung uno man yang } \\
\text { kanilan kariman. } \\
\text { Yalabay yang pilang ka tuig yang maguwang na } \\
\text { anak nilan yabarik sa bay ng kanilan babo gamit } \\
\text { yang buwawan na singsing, ya angyo yan sini ng } \\
\text { madjaw na dagom aw a usabon yang kanan indog. } \\
\text { Wa kadugay, yaga sog da yan ng madjaw na dagom } \\
\text { aw awnday binaning na panyo, na amaynang nilan } \\
\text { sakayanan. } \\
\text { Aw pagdatong nan sa bay ng kanan babo way an } \\
\text { kila'a sini. } \\
\text { E atagan nan inyan ng sadi aw yapakila yan. } \\
\text { Ya pangayo yan ng kaamponan sabap sang yama } \\
\text { inang nan na di ng madjaw kanilan maglunion. } \\
\text { Adon pagkabus yadog yan sang pangobowan o } \\
\text { lubunganan ng kanilan ina aw ama. } \\
\text { Ilukat nan yang posa ng kanilan paganak aw e angyo } \\
\text { nan yang singsing na a buhi-on mag-barik yang } \\
\text { kanilan taganak. } \\
\text { E ampowan nan yani aw e payapayan aw sidto yama } \\
\text { buhi dayon. } \\
\text { Yadog silan sa bay ng kanilang babo, aw yapanagyo } \\
\text { yani ng kaampuna sang taganak nilan sabai sang } \\
\text { way kalat nilan sang naglumon yang olitaw na usog } \\
\text { ya kadto sa kanilan e-uyan aw ikamang yang kana } \\
\text { mangkangod. } \\
\text { Aw e limayuhan nilan yang sambok na luna ng } \\
\text { kanilan babo. } \\
\text { Adon yapangayo dawman yan ng madjaw na bay } \\
\text { adto sang sino-sino. } \\
\text { Aw ansan dayon yanapa indog yang madjaw na bay } \\
\text { adto sang singsing. } \\
\text { Aw ansan dayon yapana indog yang madjaw na bay. } \\
\text { Yang ubos ng pamilya aw simabay e-imbita adto sa } \\
\text { sambok na pakaradyan o panagtipon aw pagkabus } \\
\text { sinyan ya panginabuhi silan na matingon aw awn } \\
\text { kasuwat. }\end{array}$ & $\begin{array}{l}\text { Beautiful house } \\
\text { (Madjaw na Bay }\end{array}$ & $\begin{array}{l}\text { A beautiful house for } \\
\text { Kagan symbolized a } \\
\text { social status of being } \\
\text { wealthy and of } \\
\text { financially capacitated. It } \\
\text { was reflection of peace } \\
\text { and wholesome. }\end{array}$ & $\begin{array}{l}\text { A house as compared to a home was } \\
\text { symbolically means a mere structure } \\
\text { or constructed building. It was only } \\
\text { compose of a material thing. But to } \\
\text { say beautiful house suggested societal } \\
\text { status. Symbolizes as an affluent } \\
\text { individual, wealthy, well established } \\
\text { and stability. } \\
\text { The archetype of celebration connotes, } \\
\text { victory, triumph, success, happiness, } \\
\text { togetherness, relief and especial } \\
\text { occasion. }\end{array}$ \\
\hline
\end{tabular}

In Table 2.4, the fifth Kagan poem entitled "Yang to ma Maglonon na mga Mimaylo" with an English translation of "The Three Orphan Siblings" was written in a narrative poem form, which told a story about tree orphan siblings who were living with their aunt's house however they were maltreated by her. And so, they left her house and live independently but because of their golden heart despite financially challenged an old man gave them a magical ring which help them to uplift their state of living and even raise their parents from death. Later on they have again met their aunt and they have forgiven her and live happily with their parents. Under archetypal criticism the following symbols were lifted: "Aunt", "Old man", "Oldest boy", "Water", "Ring", "Nice clothes", "Yellow", "Tomb", "Beautiful house" and "Celebration". Given the first symbol "Aunt", in many stories and literature was characterized as being terrible to their niece and nephew instead to be a second mother. Who was also having a persona and character of being witch with a dreadful aura. "Old man" has a symbolism of wisdom and the knowledgeable one.

The "Oldest boy" personified a symbolism of a second father when it comes to family responsibility. "Water" archetype signified a mystery of creation, birth-death resurrection, purification, redemption, fertility and growth. The "Ring" archetype, probably one of the famous symbols which was made popular by the movie Lord of the Ring was given a symbolism of mystery and the focal of power. "Nice clothes" directly symbolized social status and hierarchy. The color "Yellow" signified in Kagan as royalty which was associated to sunshine, hope and happiness. "Tomb" as a sacred structure where the dead are buried symbolized death, memories, soul, dark secret and connected to tragedy. While the "Beautiful house" carried a symbolism social status and stability in life. Lastly, "Celebration" was attributed to happiness, success and togetherness. This can be seen in most stories and movies and cultures which celebrated if something good happened or a victory has been achieved. 
Sultio, A., \& Gomez, D.

\section{Table 2.5}

Archetypal Analysis of Selected Kagan Poems

\begin{tabular}{|c|c|c|c|}
\hline Poems & $\begin{array}{l}\text { Signifier } \\
\text { (Symbols) }\end{array}$ & $\begin{array}{l}\text { Signified } \\
\qquad \text { (Archetypal Anal }\end{array}$ & $\begin{array}{l}\text { nterpretation } \\
\text { is) }\end{array}$ \\
\hline $\begin{array}{l}\text { Pastora Acubena } \\
\text { Pastora Acubena was the only child of Tamisa and } \\
\text { his wife } \\
\text { They were very poor. } \\
\text { The rich datu despised them and would not let them } \\
\text { come } \\
\text { To his house or worship in the mosque. } \\
\text { One day Pastora Acubena got sick. } \\
\text { No matter who treated her, she did not get well. } \\
\text { The healer from the seventh mountain told Tamisa } \\
\text { The girl would get well if she bathed in the river of } \\
\text { Jordan. } \\
\text { Tamisa asked God for help to get to that far away } \\
\text { place. } \\
\text { Then horses with wings took them there to } \\
\text { Porch of a golden palace. } \\
\text { When the datu there heard why they had come and } \\
\text { that } \\
\text { they were muslims, he served them food and took } \\
\text { them to the mosque. } \\
\text { Later when the girl bathed in the river of Jordan, she } \\
\text { got well. } \\
\text { Before they travelled home, the datu gave them a } \\
\text { Handkerchief that would help them in difficulties. } \\
\text { When they got home, they opened the handkerchief. } \\
\text { The datu of Hordan appeared and they asked him for } \\
\text { a new house. } \\
\text { In no time a big house of gold was there. } \\
\text { When the datu who had previously despised them, } \\
\text { Saw that, he invited Tamisa and his wife to his } \\
\text { house. } \\
\text { Then Tamisa became tha datu of that place and }\end{array}$ & $\begin{array}{l}\text { Seventh } \\
\text { mountain } \\
\text { (Ika pito } \\
\text { na butay) }\end{array}$ & $\begin{array}{l}\text { This signified problem, } \\
\text { trouble and sacrifice sent } \\
\text { by Allah for being } \\
\text { hardheaded. }\end{array}$ & $\begin{array}{l}\text { A sick archetype symbolized } \\
\text { challenge, difficulty, circumstances, } \\
\text { trouble, pain, sacrifice, problem. And } \\
\text { somehow it stands as a bridge and } \\
\text { reconnection towards God, through } \\
\text { this it opt people to repent their sin } \\
\text { and to have faith again with Divine } \\
\text { Creator. } \\
\text { Tracing this symbol, Seventh } \\
\text { Mountain in a biblical perspective } \\
\text { referred to the throne of God. The } \\
\text { image of a mountain which was the } \\
\text { thrones of God probably derives from } \\
\text { the mythic idea of the cosmic } \\
\text { mountain which unites heaven and } \\
\text { earth and stands at the center of the } \\
\text { world. Seven mountains was also } \\
\text { related to the perception like } \\
\text { Aristobulus of a sevenfold principle in } \\
\text { reality. The number seven among the } \\
\text { most potent of all symbolic numbers - } \\
\text { signifying the union of three and four, } \\
\text { the completion of a cycle, perfect } \\
\text { order. In literature, particularly in } \\
\text { Divine Comedy by Dante Alighieri the } \\
\text { number seven is connected to the } \\
\text { seven stages/places in the Paradiso, } \\
\text { Purgatorio and Inferno. Similarly, } \\
\text { mountain is related to a place or stage } \\
\text { which some should pass by before } \\
\text { getting to his/her destination or to the } \\
\text { seventh mountain. }\end{array}$ \\
\hline
\end{tabular}

River of Hordan The river of Jordan in

(Lawasng Kagan sense symbolized Jordan) So he and his parents went to see Tamisa. They all arranged for the marriage. Beautifully dressed they went to couple be married. Then Pastora Acubena went to live with her husband.

\section{Si Pastora Acubena}

Si Pastora Acubena yang sambok na anak ni Tamisa w yang kanan asawa.

Silan miskin gaid na pamilya.

Yang sadiyan na datu, piga daug-daug sinan aw gani di silan pag pasudon sa bay, agad pa sang

pagsambayang sa masjid.

Sangalaw, si Pastora Acubena yamasakit.

Agad e uno da yan pag bong wa gyapon ka uri.

Yang yagabong sang ika pito na butay kawngan si

Tamisa, na yang kanilan anak amadayaw gaid kung asugbuwan sa lawas sa Jordan.

Si Tamisa ya pangayo ng tabang sa Magbabaya na silan amakadatong sinyan na lugar. Aw sabap sinyan e atagan silan ng kabayo na awn panidan, aw silan e atod adto sa sambok na buwawan na bay.

Pagkatigam ng datu adto sang kanilan tod aw silan kay mga muslim ipakan nan yani aw ipasod dayon sa mosque.

Pagkabus yamakasugbo ng kanilan anak sa lawas sa Jordan yama dayaw dayon yani.

Una silan ya uri sa kanilan apit yang datu e-atagan silan ng is aka panyo na matabang sang kanilan kayrap aw sang timpo na yadatong pa silan sang kanilan bay, e abrihan nilan yang panyo yagapakita yang datu sang Jordan aw, yagapakita yang datu pureness and free from impurity. The river stands for goodness and healing place for the sick one. It is considered as sacred place also because of its historical background.

\section{God}

(Magbaba-ya/tuh a)
This signified in Kagan as Allah. And is considered to them as the supreme being of all. The divine creator and the responsible to every thing that happen.
The Jordan river historically and religiously, it is considered to be one of the world's most sacred rivers. The Jordan is a frequent symbol in folk, gospel, and spiritual music, or in poetry or literary works. Because the Israelites made a difficult and hazardous journey from slavery in Egypt to freedom in The Promised Land, the Jordan can refer to freedom. The actual crossing is the final step of the journey, which is then complete. The Jordan also can signify death itself, with the crossing from life into Paradise or Heaven.

The God archetype was directly associated to Being. God as the source of being, viewed as being the sum total of everything, pantheism. God as consciousness of being, our path to the divine as being a process of deeper knowing, of enlightenment. Carl Jung identified the God archetype with the Self and the spiritual journey as the path to self-becoming (individuation) and self-understanding. God as the unity of being, Islam believed in only one God and Buddhism expresses the unity of God, that everything is essentially the manifestation of one essential reality. God as transcendent being, Gods of polytheism were seen as embracing common archetypes such as warrior, mother, river, spirit 
sang Jordan aw yapangayo silan kanan $\mathrm{n}$ g baud na bay.

Ansan-ansan dayon sambok na buwawan na bay yang yapakita.

Sang timpo na yamahitabo inyan yang datu na ningawn yatamay kanilan, e imbitar silan sini sang kanilan bay aw sikon sidto si Tamisa yama inang na datu ng kanilan lugar.

Yang anak ng datu sa Jordan Kauni na pakawinan si Pastora Acubena, araw sa ikadtunan ng taganak ng usog si Tamisa aw e pakandori-an yang kawin. Aw sang pagkabu ng kawin si Pastora Acubena yakadto aw yaagad da mag uya sang kanan bana.

yet at a transcendent level, above and beyond our ordinary experience of them. God as the quality of being, identified as wisdom, compassion, majesty, justice and attributes related to God's being might be like. God as the wonder and mystery of being, talking about God as a quality of being the mystical tradition. God as the personal nature of being, allows people to relate to the personal dimension of being and have a relationship with it. God being itself, acknowledges God directly as being.

$\begin{array}{ll}\text { Horses with } & \text { Horse with wings or } \\ \text { wings } & \text { Pegasus symbolized in } \\ \text { (Kabayo na } & \text { Kagan as the vehicle of } \\ \text { panidan) } & \text { the good people and the } \\ & \text { great warrior. It was } \\ \text { enigmatic as its image } \\ \text { and its majestic view. }\end{array}$

Golden palace (Buwawan na bay)

Mosque

(Masjid)

Gold

(Buwa-wan) Islam religion. It is a sacred place for it is the of them. was associated with the

\begin{abstract}
The golden palace in Kagan symbolized house of virtuous people the royal color of the palace is connected to a person with a golden heart or with moral values.
\end{abstract}

Horse with wings or Pegasus symbolized and associated to mighty or strong but another connects the name with the Greek word for a spring or a well. It was enigmatic, mythical, mysterious. On the other hand, it represents values of liberty, divine force, something free and pure, brave and beautiful.

Golden palace represented good fortune, ambitions fulfilled, wealth, and prosperity. It may also indicate emotional fulfillment, as perhaps you are entering a time of happiness that is long overdue. The message here is that self-worth is not measured by what you have, no matter how abundant your life is. Instead, it comes from what you are, how authentically you are living your life, and how much love you are willing to share.

It was the symbolic place for Muslim people under praying and retreat place

The gold color in Kagan person with a golden heart morally upright. On the other hand, it was also connected with blasphemy and wickedness because of its material value that may attract immoral acts.
Symbolically a mosque was a sacred place for Muslims. It brings the community together as it acts as many things, a social center, a community center and an educational center, as it has many events which welcome both old and new members of the mosque.

This symbolized prestige, wisdom, wealth, knowledge, generosity and quality. It can represent the sun, royalty, wealth and the divine. For the Egyptians, it was linked with $\mathrm{Ra}$, the Sun God, and corn, upon which life depended. To the Hindu it was the symbol of truth. The ancient Greek saw gold as the symbol of reason and immortality. It is associated with higher ideals, understanding and enlightenment. It inspires knowledge and spirituality.

In Table 2.5, the sixth Kagan poem entitled "Si Pastora Acubena" with an English translation of "Pastora Acubena" was written in a narrative poem form, which talks about this despised family by a datu. Pastora Acubena got sick and her mother Tamisa was told to bring her to the seventh mountain where a healer can help them and she was brought there. Indeed, she was healed and knowing that they were muslims the datu there accommodated them well and even help them through the use of a handkerchief. Pastora Acubena became the datu of their place and married the good datu's son. With that, the following symbolisms were elicited from this poem: "Sick", "Seventh mountain", "River of Jordan", "God", "Horses with wings", Golden palace", "Mosque" and "Gold".

First symbol in this poem "Sick" has a symbolic meaning of being a challenge, sacrifice, problem and 
Sultio, A., \& Gomez, D.

symbolically connected to as reconnection to our divine creator. Next, the "Seventh mountain" symbolized in Kagan as a challenge or obstacle in life. Similarly, the number seven symbolized God and to follow God himself was a big challenge because we have to be morally upright and that does not as easy as what was seem to be. In literature, in the masterpiece of Dante Alighieri the number seven has a symbolic meaning since this is the last stage or place that the main character has to reach. And by that, this suggested that you have to pass six stages or obstacle before getting into your final destination. The "God" archetype both Kagan and different cultures signified as the only supreme being and the divine intervention. "Horses with wings" or Pegasus though mythic creature has a symbolic meaning of a special vehicle of the mighty warrior which similarly signified for mightiness, liberty, divine force and of being enigmatic. The "Golden palace" symbolically stands for virtuosity, royalty and prosperity. It also symbolized fulfilment in life. The "Mosque" or church signified sacredness and a symbolic worshipping place for all Islamic people around the world. Finally, "Gold" though symbolized for prosperity and wealth it is related to blasphemy and wickedness because of what it can bring to people just to possess it.

Table 2.6

Archetypal Analysis of Selected Kagan Poems

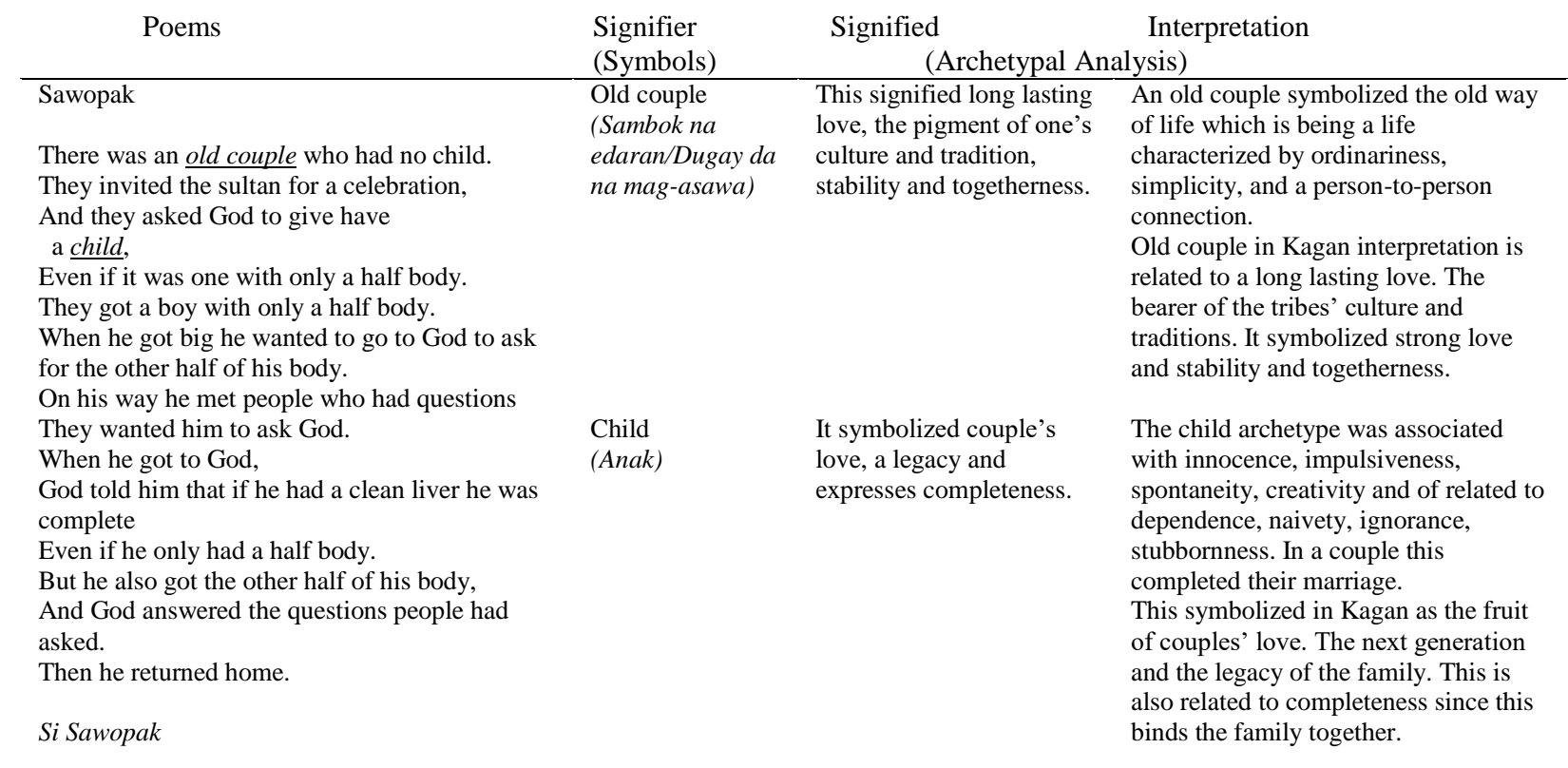

Awn sambok na edaran na mag-asawa na way anak. E imbitar nilan yang sultan para sang sambok na kandori, aw ipangayo nilan adto sang tohan na a-atagan silan ng anak, agap pa yani katunga da yang lawas.

Aw asinyan, silan ika anan ng sambok na og na awn katunga sang kanan lawas. Sinyan na timpo yaturan $\mathrm{g}$ iso na yang kanan kalini ama tubang yang tohan aw apangayon yang katunga ng kanan lawas.

Sangwn mga isi kanan pagpadug adto sang tohan yamasugat nan yang mga otaw na awn mga isip kalini nilan usipon yang tohan. Aw sang pagdatong nan adto sang tohan, aw kawngan yan, na kung yan awn malinis na atay yan kay kompleto, agad pa awn gaid tunga ng kanan lawas.

Agad pa yamabati nan yang katunga ng kanan lawas aw itubag ng tohan yang mga usip ng mga otaw.

Pagkabus sinyan yabarik yan mag-uri kanilan.

In Table 2.6, the sixth Kagan poem entitled "Si Sawopak" with an English translation of "Sawopak" was written in a narrative poem form, which basically narrated the story of this old couple who has no child before 
but were then given after praying from God. However, the child has only half body and when the boy got matured, he then asked God for the other half of his body. This will only happen if he has a clean liver and so, he got the other half of his body. From this poem after archetypal analysis has been made two major symbolisms were lifted: "Old couple" and "Child". An "Old couple" on one hand, signified in Kagan as someone who represented the state of being togetherness, a long lasting intimate relationship and someone who stand for the cultural heritage of a tribe. In connection to this in "Old couple" it is also association to being ordinariness, simplicity and a strong connection to each other. The last symbol "Child" signified in Kagan as the fruit of two in love couple and legacy and it is also symbolized as the binder of the family. This in a broader sense the "Child" archetype symbolized innocence, impulsiveness and naivety.

\subsection{Research Question No. 2: How does the Kagan tribe preserve their poems?}

In view of the second research question, in-depth interview and focus group discussion were conducted to the target informants. Further, interview guide related to the research question were asked to bring about ideas and information regarding their practices, culture, tradition and poem preservation. After the data collected and were grouped, significant themes were lifted. Presented are the emerging themes and core ideas from the informants' responses, which are based from their personal experiences as part of the Kagan tribe. With that, four major themes emerged: Use poems as lullaby, teach poems to the youth, let children repeatedly recite the poems and showcase the poems in social gatherings and special occasions.

Use Poems as Lullaby - It was revealed in the focus group discussion that poems were introduced by the Kagan elders in a form of lullaby to their children during sleeping time. It was the common answer among the informants during the discussion. As they added, in this manner they were inculcating to their mind informally their poems to the young. In the statement of Tita (pseudonym) it was shown how lullaby was used as a form of informal teaching of their poetry, as follows:

"Sang timpo na iso pa silan, inyan yang piga gamit na pangkatog minang lullaby yang piga kanta ko kanilan. Sa sigeng kanta aw permi nilan magkadungog taman na ama familiar yang tula ng kanami tribo." (FGD-Res. No. 008)

(I used to sing it with them when they have to sleep like a lullaby. And so, as they repetitively hearing it these will become familiar to them.)

To add, in support to the above theme Chuabbz (pseudonym), that in the event the she has to bring her grandchildren to sleep and sung these poems to them. And by this, they will be exposed and be familiar with their poems.

"Yaona japon sang ilawng nilan, yang kanak gaid na kong malog da silan amatog kong a linisan nilan yani o a-unawan yang kanilang anak na-akantan nan yang sang kanami moa tula. Para uman amalingaw yang mangayso." (FGD-Res. No. O11)

(During bed time I sung these poems to my children and even to my grandchildren so that they will remember our poems in their early age.)

Further, Healer (pseudonym) said that they have repetitively saying these poems and used it as a lullaby to their children. And he encouraged the coming generation to teach these poems to them.

"Piga gamit name yani na pampakatog taman sa amakaringaw yan sang kanan piga dom-dom. Agaw sa yang kanak piga lawng sa ina nilan na akanta-kantan nilan. Bali-a pabaylnagan nilan Aw pinaagi sini amakatadom silan kong uno kadjaw yang dumadatong." (FGD-Res. No. 009)

(We used these poems as a lullaby to the children until they will fell to sleep. Likewise, I encouraged their mother to sing these poems to them.) 
Sultio, A., \& Gomez, D.

Therefore, poetry in Kagan culture was not just an expression of one's feeling of emotion but it was creatively used as lullaby for children. This claim was supported by the statements and ideas of the research informants.

Teach Poems to the Youth - It was revealed during the in-depth interview and focus group discussion, that one way to preserve the poetry of Kagan tribesmen was through teaching their poems to the youth. Through such act they can ensure that these poems will proliferate throughout the years. In the statement of Mamma (pseudonym) evident was the idea of direct teaching to the youth about their poetry.

"Sang kanak kabahin sir, di pinaagi sang pagkanta kung di kanak gyod a lawng sa kanak mga ompo. Alawng ko jud kanilan yang kanami ka-ompokan yang kanami isikohan pati da yang kanami tula. Pinaagi sini silan amakapag aw kung uno uman yang kanilan dayt inangon sa kanan adon na panahon." (FGD-Res. No.012)

(In my own point of view, I directly teach to my grandchildren about our cultural and literary heritage. By this way, they will know how to act on these poems amidst the new millennium.)

Imam (pseudonym) stressed that teaching about their poetry and culture to the young will help to preserve their literary treasure.

"Pinaagi sang pag-inog sang mga madjaw na butang kanilan aw pinaagi uman sini amapadag kanilan yang ka importantehan sang kanami ginawa na mga tula. Pinaagi sang tula akaindo ko kanilan yang mga madjaw/dayt tarong na a-inangon." (FGD-Res. No. 010)

(Through teaching about good things and at the same time highlights the importance of our poems to our culture. By this I will be able to teach values through poetry.)

In like thought, Earnest (pseudonym) accentuated that repetitive teaching to the youth has a significant factor in the survival of their poetry. Through constant review of these poems to them will help to secure it.

"Para kanakon, piga balik-balik ko gyod kanilan o piga review yang mga paglawngan o kadaygan pa na mga tula ningawn. Latoi da yang mga folktales a basahal ko aw a istorya. Piga balik-balik ko gyod pag isawng aw pagkanta kanilan.” (FGD-Res. No. 013)

(For me, I have repeatedly taught and reviewed to the youth about our poems, folktales and short stories. I repetitively narrated and sung these to them.)

Moreover, it was magnified by Chuabbz (pseudonym) that direct teaching was one way of preserving their poetry.

"Sa ako pud kabahin, ako pung tudloan ang akong mga anak sa dapat nga buhaton sa among mga tula. Og ako pung isulti ang mga tulang Kinagan.” (FGD-Res. No. 011)

(On my part, I have taught my children about the right things to do about our poems. Likewise, I directly taught them with the Kagan poetry.)

Therefore, Earnest (pseudonym) confirmed that direct teaching has a vital role in the perpetuation of their poetry.

"Sa kanak, piga lawng ko sang kanak mga umpo. Piga lawng ko japon aw piga pa balik-balik kanan aw piga pa memorize kanilan yang mga folktales aw tula na piga pa balik-balik maglawng. Agad di sa pagpakatog agad uno na oras minang piga singit ko na maglawng kanilan para di nilan akaringawan. Sikon sang kanilang pagkaiso sa adon na panahon, piga pa istorya ko yani, man japon yani aw yagapabilin untak ama-preserve yang mga tula." (FGD-Res. No. 013)

(What I did, was to directly teach them our poems. I constantly teach them about these literary 
pieces. Any time of the day I find ways to insert it so they will be able to understand and memorize these. In like manner, they have to do it in the forth coming generations.)

Talkie (pseudonym) added that teaching of their poetry to the young will help to protect these poems.

"Naga ingon mi sa mga bata nga inyo ning paga sundon. Amo gyod ginapasa og ginatudlo pud sa mga bata nga aron dili pud nila ni makalimtan og kini magpadayon hangtod sa hangtod." (IDI-Res. No 001)

(I have made clear to them, that they should follow and learn our poetry. In like way, we have passed and taught to the children these poems so that they will not forget and these continue to illuminate through the ages.)

An effective way of inculcating poems to the minds of their future generation was through directly teaching these to them. It was through this technique that they can ensure to educate the young about their poetry.

Let Children Repeatedly Recite the Poems - During the conducted interview and discussion, one of the themes was allowing the children repeatedly recite the Kagan poems. The informants' statements revealed that to preserve their poetry was to let the children be the carrier of their literary pieces. It was revealed in the idea of Maester (pseudonym) as given below:

"Yang pagpreserbar sang tula name, paagi sang pagsigeng indo na yani yang tula, piga balik-balik ontak taman sa taman akatanduman nilan” (IDI-Res. No.002)

(We constantly made them hear and teach our poems until they will be able to memorize it.)

Sophie (pseudonym) magnified the idea that repetitive teaching and reciting their poems will lead to the preservation and understanding of their native poetry.

"Yani pinaagi sa pagbalik-balik pag kanta o pagpresenta sang kadaygan untak di yani akaringawan akapagan pa gyod yani." (IDI-Res. No. 003)

(This was done through repetitive singing and presenting these to everybody so that these will not be forgotten but will be understood by the youth.)

Importantly, Tita (pseudonym) emphasized that they recited and presented their poetry to the youth with sincerity and passion so they will be able to see the true meaning of every poem.

"Pasaya name yang kanami mga tula, ipasaya name yani aw piga gamit. Bilang sambok na lider aw kadaygan sang mga Ka-ompohan sa Kagan, yama inang kami role model o madyaw na imahe sang mangayso na mga Kagan. Aw piga pakita nami kanilan na pasaya jud name yang kanami kultura” (FGD-Res. No. 008)

(We really do love and value our poems; as such we ourselves recited and preserved these poetic traditions we have. As elders of the tribe we lived as a role model to the young generations.)

Thus, in the answer of Earnest (pseudonym) revealed that repetitive teaching and memorization of their poetry are important in securing their poems.

"Yan man jud yang permi na piga pasabot na mga tradisyon aw kultura na mga Kagan. Sang makto to makto a permihon mag tudlo sang mangayso onta di amatanak aw pi akaringawan." (FGD-Res. No. 006)

(And so, I have constantly emphasized our culture and tradition that as much as possible these should be learnt and acquired by the children and to also give importance to our poems so these 
Sultio, A., \& Gomez, D.

will not vanish and forgotten.)

Protectress (pseudonym) claimed that poem reciting has an important part in their cultural proceedings.

"Ako bilang balyan, di amatanak yang pagbayuk basta awn kanak ritwal na piga inang magsod gyod yaning pagbayuk.” (IDI-Res. No. 005)

(As a cultural master, poem reciting has always a vital part in any ritual I made.)

Constant practice leads to mastery; this was the principle holding on by the Kagan tribesmen. It was through repetitive reciting their poems will help them attain stability and quality.

Showcase the Poems in Social Gatherings and Special Occasions - Social gatherings and special occasions has a crucial role in the transmission of Kagan poems and culture to the next generation. It was during these times where they can present their poems to the youth. Inasmuch that they are gathered during an event, it will be the best time to inform everyone about their literature. As discussed by Maester (pseudonym) that during traditional gatherings they are presenting their poems to the majority.

"Yang pagpakita name ng pagmahal sa kanami isikonan o apabila sang kanami mga tula, piga atagan o piga gahinan jud na nami ng alaw sa paggamit sining kanami mga tula, piga gahahinan gyod name yani ng alaw o okasyon na yani an alaw piga present. Parehas sang awn kawin piga pakita aw piga pabasa. Awn kanami mga selebrasyon o gathering nay an yang piga pakita aw adon sa City parehas sang sa Pakaradyan. Aw adi piga pakita name yang tradisyon ng mga Kagan yang kanami domain sa pagda awn amapakita” (IDI-Res. No.002)

(Our deep concern and love to our poetry can be shown through constant practicing of it. We see to it that we have make time like special occasions where they can pre-sent to the youth their poetry. A celebration like Pakaradyan, where they showcase the Kagan tradition.)

Sophie (pseudonym) supported the former statement that it was through special occasions or celebration that Kagan tribesmen present their poetry.

"Yang isa sa pagpreserba ng kanami mga tula sa Kagan tribe yani pinaagi sa pagpakita sini apabila awn mga aktibidad kamag-unawa sang Kaimunan aw Pakaradyan. Yani amapakita pinaagi sa pagshare sa mga tula. Adto sa mga olitaw aw daga na mga Kagan. Aw kabahin sini yan yang pagparecite sang batan-on kong awn maga tapok na tribong Kagan.” (IDI-Res. No. 004)

(If there are activities like the Pakaradyan and Kaimunan we were presenting it so that in this way we will be able to share to the children the poetry of the tribe. And they are also asked to recite these poems to everybody.)

Moreover, Maester (pseudonym) has stressed that special events became the avenue in poetry preservation of Kagan people.

"Sa adon awn da may programa ng siyudad aw sa pag-indo adto name piga pakila. Pinaagi sang tribal meeting ng magkalahi-lahi na cultural classes adto name yani piga pakita kung uno kadjaw yang a-inangon." (IDI-Res. No. 002)

(These were presented during special gatherings or meeting and program about the indigenous people.)

Special event and social gathering highlighted celebration and happiness, but in Kagan people it was also the right time to present and introduce their literary heritage especially their poems to the youth. This underscored their poetry in order to perpetuate these.

308 Consortia Academia Publishing (A partner of Network of Professional Researchers and Educators) 
4.3 Research question No. 3: What are the hopes of the Kagan tribe about their Poems and Literature as a whole and to their race?

From this research question the following themes were lifted and presented. During interview participants have given their responses basing on their personal experiences and knowledge. And so, emergence of the following themes, to wit: Poems and Literature be preserved, Literature be handed down from one Generation to Another Generation, Continuously Educate the Youth about Kagan Literature and Practices, Use Modern Technology as Archive of Kagan Literature, Kagan's Cultural identity as Tribe be reflected in Poems and Kagan Literature and Cultural practices be Appreciated. Presented hereunder were the Themes and Core ideas about the hopes of Kagan tribesmen to their poems, literature and to their race.

Poems and Literature be preserved - In this theme, it was cleared that the Kagan people hoped to preserve their poetry and literature. It was through poem preservation bring forth these write ups to the coming generation. Kagan has an aspiration of seriously document their oral expressions and compile these into single collection. For that reason, their vision and aspiration was to make these carefully safeguarded and well-kept for its proliferation and for the future of Kagan tribesmen. Earnest (pseudonym) point out:

"Permi na piga pasabot nilan untak ama preserba gyod yang kultura aw tradisyon isawru man ng mga tula aw folktales. Unta presko permi sang kanilan domdoman na amada gyod adto hangtod sa hangtod da sa sunod na henerasyon." (FGD-Res. No. 006)

(I made them understand that we have to preserve our culture and tradition like as well the poems and folktales of the tribe.)

In like manner, Healer (pseudonym) magnified that these poetry and literature of the tribe must be preserved. In any social gatherings these should also be given emphasis and be introduced to the young ones.

"Dapat ama-preserba gyod yaning mga tula aw a-indo sa kanilan mga anak aw mga ompo. Kay kung di uman silan mapakita sang mga party o pagtapok ng mga Kagan di uman silan amatigam kung uno yang piga inang ng mga Kagan na kung awn mga gathering yang Kagan dapat iyan silan untak amakita nilan yang mga kultura na ininang. ” (FGD-Res. No. 002)

(I urged everybody to teach these poems of us to their children and even to their grad children. In like way, they should also participate in any gatherings and activities of the Kagan because during these times culture and tradition were highlighted.)

As supported by Talkie (pseudonym), it was her heartfelt gratitude to their ancestors because through them these poems were created. And so, these should be preserved and be taken care off.

\begin{abstract}
"Mapanginsokoran uman ako sang kanami mga tula na ininang pa ng kanami ka ompowan na yani ama preserbar pa aw akadatongan pa sang dumadatong na shabab. Amasurat dawman mayo na yang mga yagapangarap yang kamayo uman yaning ama dokumento mapanginsokoran uman kami san” (IDI-Res. No. 001)
\end{abstract}

(I am very much thankful to our great ancestors for all of these poems they have composed. And the need to preserve all of these is important to the coming generation. Thus, I prayed that these poetries of us should also be scholarly documented.)

In a similar idea, Servant (pseudonym) expressed his aspiration to put these poems into writing better yet compile these in a single book. Through such way, we will be able to secure and protect the Kagan poetry and literature.

"Gaw na amalibro yani aw gaid dapat na aprotektahan yani aw para di basta-basta na 
Sultio, A., \& Gomez, D.

amagamit sa di ng madyaw" (IDI-Res. No. 006)

(I am hoping that these poems will be written into one book of information. By this, our poetry will be protected and conserved)

Moreover, Tita (pseudonym) accentuated the beauty and importance of preserving their poetry and this should be instilled in the minds of our new generation.

“Apakita kanilan kung uno yang kadjawan na amakamang sa kanami ginawa na mga tradisyon aw kanami mga tula. Yan pinaagi sa pagsigeng pakita aw padungog kanilan sang pag kanta aning mga tula taman na sila ba mismo yang amatigam san.” (FGD-Res. No. 008)

(I will show them the importance and beauty of our poems that these must be protected and preserved for the future generation.)

Poetry and literature preservation was a just process to do, given the fact that these were not yet formally written and documented. Evidently, Kagan aspired to document these in order for the next generation to appreciate and understand. Therefore, compilation and analysis of their selected poems ensured its perpetuation and survival in the coming new society.

Literature be handed down from one generation to another generation - The second theme lifted in this third research question was the transmission of literature from present generation to the next generation for the purpose of preservation and literary stability. It was found out that Kagan tribesmen want to pass their literary traditions to new generation in order to perpetuate such poems and other literary expressions of the tribe. Hence, it was their hope that the youth themselves be the carrier and protector of their literature. This was provided in the idea of Shyness (pseudonym) as stated below:

"Kung uno man yang kanak isundog sa kanak mga piganak na Kagan, sang kanaka ma sa madjaw na pamatasan inyan uman sang kanak akabilin sa kanak mga anak.” (IDI-Res. No. 014)

(Anything that I have acquired and learned from my parents I hope that these will be continued by my children and Kagan people.)

In similar way, Tita (pseudonym) accentuated the thought of handing down their literature and culture to the next generation to ensure its quality and meaning.

"Bilang Kagan dapat amapasa gyod sa sunod na henerasyon yang kanami mga tula, tradisyon aw kultura na mga pamaagi aw ininang" (FGD-Res. No. 008)

(As part of the Kagan community it is a must of handing down our poems, tradition and culture to the next generation.)

Truth to be told, Protectress (pseudonym) emphasized the importance of documenting their literature as an obligation being a Kagan member of the tribe.

"Yang kanak gaid angyo na yani ubos na ininang aw mga tula sa Kagan na yani mapadayon untak di akaringawan kay wada yani, waday ama inang, amatanak yani.” (IDI-Res. No. 007)

(I hope that the Kagan poetry will continuously appreciate and practice these literary pieces. So that these will not be forgotten but rather flourish.)

Congruent to that, Healer (pseudonym) stressed that whatever he has acquired and learned from his parents he wanted to pass it to the present generation for them to continue what was being started before.

“Kung uno man yang kanak piga inang sa pagkakagan inyan oman yang apainang ko kanilan 
aw yani ama preserba oman nilan aw yani magapabilin japon, apabila ama tanak ko yaning kanilan ama." (FGD-Res. No. 009)

(Whatever I have learnt from the past I want also them to practice and continue these. With that, they will be able to do it even without me.)

Wherefore, handing down the literature of a tribe ensured the stability of their culture and tradition. Likewise, in the case of Kagan literature they also hoped to secure their literary pieces for the benefit of the future generation.

Continuously educate the youth about Kagan literature and practices - The next theme generated from their responses was the importance of education to the Kagan people about their literature and practices. They emphasized to instill to the young minds of the new generation about the Kagan masterpieces and traditions. This was provided in the idea of Earnest (pseudonym) the importance of educating the youth about the aforementioned.

\section{"Kuwan gaid jud permi gaid yang pag indo kanilan. Constant ba, minang constant practice sang kanami mga ininang. Untak di yani akaringawan." (FGD-Res. No. 013) \\ (Constant teaching them about our practices in order for them to fully understood and retain to their mind all of these.)}

As emphasized also by Maester (pseudonym) they were doing their best to seriously instill and educate the youth about their literature and practices for the survival of their culture and race.

“Yang pamaagi pigapasa sa sige-sige pag relate kanilan kung a unom idto, piga relate nami sa kanilan kinabuhi para akadagan gyod nilan yaning kanami mga tula, na amabutang gyod nilan sang kanilan domdoman aw pangarayan nay an yang kabutang ningawn pinaagi sini akadagan nilan yang kanami tula” (IDI-Res. No. 002)

(A repetitive teaching and application of this in a practical situation so, they can effectively understand all of these. By this, they will be able to understand through their mind and soul about the literary heritage of Kagan tribe and will really comprehend our poems.)

Henceforth, as added by Maester (pseudonym) that they have spare time solely for teaching about their cultural practices and literature.

"Yang kanami piga inang kay yang paggahin ng panahon san a butang. Na sa yan na araw yang gaid yang a inangon nilan para gaid gyod akadagan nilan yang kanami mga tula. Aw apakita uman name yani kanilan." (IDI-Res. No. 002)

(We will spend a day with them without doing anything but solely presenting our poems and culture.)

Thus, the value of education may it be formal or informal significantly safeguarded the literature and practices of the Kagan tribesmen. Educating the youth being the carrier of the culture and tradition of the tribe is a crucial part in literary preservation. Quality and meaning are the things to consider in doing so. Hence, the elder's knowledge and wisdom should be handed down carefully.

Use modern technology as archive of Kagan literature - Another theme lifted from the research participant's responses was the used of modern technology as medium for archiving and repertoire of information of Kagan literature. It was elicited from the informants that new technologies were beneficial in recording of Kagan culture and literary expressions. Hereafter, the role of these technologies was crucial in ensuring the preservation of their literature. As being stressed out by Imam (pseudonym) the used of modern technologies are primarily for preservation. 
"Importante gihapon yaning mga bago na teknolohiya sabap pinaagi sini amalawng mo yang kanimo mga ininang aw ama preserba yang kanami mga kultura na ininang ng mga Kagan” (FGD-Res. No. 010)

(By the use of modern technology we will be able to transfer and preserve our culture for the next generation.)

Likewise, in support thereto Earnest (pseudonym) accentuated the idea of modern technologies as a tool in culture and literature preservation.

"Dakwa gyod yang akatabang sining bago na teknolohiya sa social media parehas sining minin na interview agad di mo magkakita pero magkadungug. Yang advantage san magkakita gyapon yang bago na henerasyon yang na interview aw yani ama-preserba ng madjaw yang resulta san magpabilin yang tradisyon aw kultura na bowi pinaagi sini adon na mga teknolohiya" (FGD-Res. No 013)

(The benefit of modern technologies and social media, these will help to perpetuate the cultural practices of the tribe. Like for example this interview will be recorded and be studied.)

In similar manner, Maester (pseudonym) pointed out the essential use of modern technologies in showcasing the Kagan tradition, poetry and culture not just nationally but even in the international community.

"Isa da na instrument na amagamit name untak amapakita sano tibook dunya o sa kadaygan sang social media, amapakita aw akatigaman na yani yang kanami tradisyon tula aw kultura sang kadaygan nga yani yang kanami piga inang, kanami yani, kanami kultura bilang sumbok na Kagan." (IDI-Res. No. 002)

(This is one of those instruments that we can use to present worldwide about our poems, culture and tradition being a member of the Kagan community.)

With that being said, Sophie (pseudonym) highlighted her idea about the use of modern technologies in perpetuating and conserving the Kagan poetry, literature and culture. It was through such thing the future generations be able to appreciate and understand all of these material and non-material culture of Kagan tribe.
"Yang mga bago na teknolohiya awn madjaw na bunga adto sano pag preserbar aw pagprotekta sa kanami mga tula, literature aw kultura, kay pinaagi sang paggamit sini amabasa, akadagan aw amakita pa sa dumadatong na nenerasyon kung uno man sang ari-anan ng kanami tribo. Aw yani uman para ipakita aw ipasabot sa mga dumadatong na mga researcher awn mga proseso na awn dapat asunopon." (IDI-Res. No. 004)
(These modern technologies have positive results in terms of preserving and protecting our poems, literature and culture. Through these, the new generation will be able to utilize, read and understand things which were handed down from us by our ancestors. Meanwhile, researchers have to follow standard protocol.)

To sum it up, Guru (pseudonym) emphasized the vital role of modern technologies in poetry preservation and safeguarding.

"Pinaagi sini mas malog yang pag preserba aw pagprotekta sang kanami mga tula” (IDI-Res. No. 005)

(Through these we will be able to preserve and protect our poetry.)

Henceforth, indispensably the benefit of modern technologies both in preservation and safeguarding the Kagan literature and culture were valuable in so many ways. It was through these technologies will harness the Kagan 
tribesmen to treasure their native imprint. And so, these serve as a repertoire of Kagan literary and cultural information.

Kagan's cultural identity as tribe be reflected in poems - Literature and people were connected and inseparable. Humans express their feelings and emotions through literature. Unveil in this theme that Kagan cultures were reflected in their poetry. The Kagan identity as a unique tribe mirrored in their poems and was creatively expressed in it. Provided herewith, in the insight of Maester (pseudonym) about the unique quality of Kagan which expresses simplicity and explicit.

"Silbi, yang kalahian san kanami mga tula aw ikompara sa lain kay malog gaid sani sabuton. Kay sang kanami mga tula yaga tuyok gaid sa pag alaw-alaw na panginabuhi sa mga Kagan. Literal yang kanami mga tula aw simple gaid yani na pagka inang. "(IDI-Res. No. 002)

(The Kagan poems are simple to understand because it revolves around the Kagan's daily lives and these were written in a simple way.)

Provided as well by Tita (pseudonym), that one of the quality of Kagan poems were the way of pronouncing words and used of language.

"Naa gyod dakong kalainan ang among mga tula sa lain ilabi na sa paglitok og sa mga pinulungan nga ginagamit. Makit an nato ang kultura sa Kagan pinaagi sa lengwahi sa Kagan sa among mga tula." (IDI-Res. No. 001)

(We are different when it comes to word choice, pronunciation and language usage.)

Additionally, Protectress (pseudonym) expressed the idea of distinguishing Kagan poetry through its tone and accent.

"Yang kalahian ng tula sa Kagan aw sa lain na tribo yani amakita pinaagi sa kalahian ng tono aw accent" (IDI-Res. No. 007)

(The difference of Kagan poems from others is its tone and accent.)

Sophie (pseudonym) elaborated the idea that through poems Kagan have able to express their one of a kind characteristic, beliefs, traditions and kind of livelihood.

“Gamit yang kanami mga tula, amapakita nami pinaagi sini yang kanami identidad sa pamaagi ng pagpakita sang kanami mga tula na gaming kagawian, pamatasan aw usahay kaugnayan sang kanami panginabohian tribong Kagan.” (IDI-Res. No.004)

(Through our poems it can be expressed the Kagan identity such as beliefs, practices, values and livelihood.)

Further, Servant (pseudonym) drew attention to the Kagan association of their poetry to usual happenings about their surroundings which also became the subject of their piece.

"Piga presenta yang mga tula sa Kagan yang mga usual na kanilan piga inang aw mga yamakapalibot kanilan.” (IDI-Res. No. 006)

(The Kagan poems present the usual happenings of their life.)

Guru (pseudonym) underscored the Kagan poetry which embodied a picturesque of humanity, important places and exquisiteness of a woman.

"Sang Kagan yang ubos na piga inang na poem sa Kagan yang pananaw sa mga panginabohian, pagka-oraw, kagwapa ng bobay, kadjaw ng lugar aw etc. sa sambok gaid na paglawngan sining 
Sultio, A., \& Gomez, D.

kanami culture sa Kagan.” (IDI-Res. No. 005)

(All of our poems describe the Kagan livelihood, wellbeing and the beauty of a woman and beautiful scenery. And one thing is important it represents our culture.)

Therefore, the Kagan's aspiration, belief, tradition and culture were all reflected and observed with their poetry. It was a manifestation of their exceptional form of poetry with regards to the above-stated distinguishing qualities.

Kagan literature and cultural practices be appreciated - Written expressions and cultural practices do not just end to that, these are to be given value and be appreciated. With that being said, the last theme emerged was literary and culture appreciation of the Kagan tribe. As supported by Guru (pseudonym) she provided the idea of putting pride and honor towards their literary writings and race.

"Ako yaga hinaot na yaning ubos apadayon aw aatagan ng halaga sa kadaygan labi da sa mga Kagan kay silan yang mada ng kanami tribo sa dumadatong na henerasyon. Na abutano nilan yani sa kanilan domdoman aw pangatayan na sani yang kabilin ng kanaton kamatikadongan. Unta ang poem na kana maka encourage sa mga umaabot ipadayon nila ang mga poem sa mga katigulangan sa pagpadayon an sila na mismo ang maghimo na mas de kalibre sa mga nauna pa. I hope nga maga lider maghimo ug programa sa mga umaabot aron ma-encourage nga magtuon." (IDI-Res. No. 005)

(I pray that all of the Kagan practices will always remain in their mind and hearts as they go along with their respective journey and continue to perform these. Because these were the treasures of the tribe handed down by our great ancestors.)

Furthermore, Earnest (pseudonym) putted emphasis on literature and culture appreciation of Kagan and gave a high regard to these.

"Yang kanak gaid na dapat a practice gain jhud yan. Tugon-tugon a practice jhud yani untak di yani amatanak. Para kanak matas yang kanak pananaw sang tradisyon aw kultura ng Kagan. Kailangan di gyod yani amatanak taman $n$ ataman man jud yan. Sa bago na henerasyon di jud yan amatanak aw sa pagka adon dapat ama ugot yan.” (FGD-Res. No. 013)

(My point was that these should be constantly practicing to avoid its extinction. My high regards for our Kagan culture and tradition. And so, I found the urgency to preserve and proliferate for the coming generation. In fact, now is the right time to reserve its quality and meaning.)

\section{Discussion}

Primarily, the ultimate objective of this phenomenological-archetypal research study was to elicit the archetypal features in Kagan poetry in Tagum City, Davao del Norte. In consonance thereof, this study focused on exploring the inner culture of the tribe by eliciting insights and perception from the participants. In this mode, we found out the core idea from the findings. Guided by the idea of Giorgi (2009) and Moustakas (2014) about qualitative research approach this underpinned the qualitative investigation. I found the feasibility and meaning in applying this approach towards extracting information to the target informants. It was in this manner be able to answer regarding the archetypes found in their poems and their interpretation, which at the same time uncovered their ethnic practices towards poetry preservation and views about their group. Importantly, part of its framework that the 14 participants are divided in to two, seven for in-depth interview and seven for focus group discussion; these were purposely invited to serve the focal aim of the study. It was through this that thoughts and insights about their poetry and culture had better illustrated. Given in the inclusion criteria informants of this study were all Kagan people in the City of Tagum, Davao del Norte. Exactly, these participants were all knowledgeable about their culture, tradition, language and literature. 
The literary features of Kagan Poetry using Archetypal Approach. In order to identify the archetypes and symbolisms in selected Kagan poems, I analyzed the downloaded Kagan poems and identified the signifiers with what it also signified according to the tribe. Since the analysis was under archetypal approach of literary features, emphasized were the symbols or archetypes present in the selected Kagan poems. Hence, any other literary features were disregarded but focused across archetypal criticism. Furthermore, archetypal patterns in poetry hypothesized racial memory and it was the shared cognitive background in every human family. Essentially, archetypes in literature and art were character, tradition, an event, a story or image reappears in different cultures across periods of time. Further, Archetypes can be seen as or in the form of stories, characters, and symbols and must be universal (Jung, 1955; Walker, 2002). Expounded hereunder were the symbolisms from the first poem of Kagan which underscored their ideas, thinking, culture and tradition.

The first Kagan poem entitled "O Kay Pasaya" with an English translation of "Oh Sweetheart" talked about the lover's forever commitment of his/her love and affection towards his/her lover that wherever he/she goes the love remains. The following symbols were; "Sweetheart", "Far place", "Heart", "Marriage" and "Work". Throughout the history and across different culture and western nationalities the "sweetheart" symbolized term of endearment as it was an expression of love towards the romantic partner. The "far place" symbol as it was used in the poem expresses a journey of the lover, wherein he/she will be separated to his/her lover for some time. In literature this signified for a distance or journey before a reunion will happen between two lovers and comparatively to Kagan sense this refers to unreachable place. The "heart" archetype symbolized as the sit of wisdom for love and affection and the same was to Kagan interpretation as it signified for the central of emotion, feeling and love. As it was presented in the poem this was the keep of his/her love for the special person he/she referring to. The "marriage" symbol which across different cultures agreed to the symbolism it represent, as a ceremonial activity that symbolically binds two individuals who have mutual feelings and affection towards each other. The same was given by the Kagan people and according to them this has brought happiness and contentment. The "work" archetype was stated as "After I finish my work," the hero or lover undertook some long journey during which he or she must perform impossible tasks, battle with monsters, solve unanswerable riddles, and overcome insurmountable obstacles in order to get back his/her loved one.

These were the enigmatic forms which personified and concretized in a repetitive images, symbols, or patterns, motifs, recognizable characters. Likewise, under archetypal images and story patterns inspired readers to make involve ritualistically of beliefs, fears, and anxieties of their generation (Delahoyde, 2011). Below were the symbolic patterns gathered from Kagan poetry. With that, Kagan poem entitled "Magaokano Ako" with an English translation of "What Shall I Do" dealt with the lover's praying to be remembered by his loved one and not to be forgotten. That despite the distance and space may his lover still committed and treasured their promised love for each other. The following symbolisms were elicited; "Melancholy", "Lover", "Resume our loving", "Return our past", "Past days", "Learning of our love", "Happiness of my heart" and "Strength of my body". "Melancholy" signified trying times and associated to extreme emotional challenge which was an expression of intense emotion felt by someone when in opposite end of the spectrum. The symbol "Lover" signified for the one who was being loved and the one who love someone, who is considered to be the source of inspiration and motivation which is not solely limited to sexual attraction.

In the symbol "Resume our loving" signified renewing the romantic feeling after was being challenged by time and destiny. In like way, "Return our past" signified for remembering the sweet memories of two individuals and implied for a second chance. The "Past days" symbol directly symbolized special events which were cherished by both lovers. "Learning of our love" on the other hand signified reawakening of couple's intimate relationship after has been challenged by tragic circumstances. The "Happiness of my heart" signified someone who was the source of inspiration and motivation. This pertained to the happiness brought by someone in a most special manner and unexplainable in thoughts and words. Lastly, in the symbol "Strength of my body" signified in Kagan and archetypal sense as someone who was the root of strength and someone who was an inspiration. Also, an archetypal mantra stressed that an intuition is the key tool to unlock the messages of an art. Wherein, intuitive imagination is the important factor which enlightened the work of art accompanied with 
meaning interpolated to Blake (1954). Hereafter, provided was another selected Kagan poem.

In the third Kagan poem entitled "Yang Otaw Magkaombok" with an English translation of "People who are in love" talked about a couple who were deeply in love to each other and were so overwhelmed with their passionate feelings without noticing that time has passed and everything has come to an end. That time is inevitable as to death is unavoidable. After an analysis was made the following symbols were lifted: "Life", "World", "Feast/Happy experiences", "Days and Nights", "Trouble", "Worlds is passing by" and "Death". The "Life" symbol in a general sense it is compared to a life of cosmos and because of its growth and changes every stage of which should be cherished as it is characterized by the Kagan people. While the "World" archetype does not directly pertain to the physical world but to the persons who were really dear to you, which likewise you considered as blessings. The "Feasts/Happy experiences" symbolized happiness and celebration which resulted to new changes and signals that something would happen. On one hand, "Days and Nights" in general reference these symbolized new beginning and an end. These symbolized birth and death respectively. And "Trouble" symbolized across literature and cultures something that bothers someone may it be caused by chaos, calamity and social, economic and personal trouble. "World is passing by" symbolized temporariness and momentary.

Literally, archetype refers to first print meaning images in the human mind present since the dawn of time. This point of view considered as the building bricks of the consciousness which are recurring in literature, art, and architecture of various cultures around the world (Jung, 1968).

In Kagan poem entitled "Putri Rangkamanis" with an English translation of "Princess Rangkamanis" was written in a narrative poem form, narrated the story of a princess named Rangkamanis who became the trophy to someone who has had healed her mother. She had married the healer whose name was a secret to her sisters, but she has disclosed this which made to forgot her own name and made to separate from each other. And later on found their ways to meet each other again. The following symbols were lifted: "Wife got sick", "Healing", "Snake", "Snake transformation", "Secret", "Handkerchief", Tigers, Lions and Elephant", "Cliff", Wild chicken, Kingfisher and Hawk", "Old woman", "Bread" and "Transformation". In the case of the symbol "Wife got sick" signified a broken vow for Kagan and in the interpolation of archetypal analysis it is related to a trouble that may cause problem to the family. It was a curse thrown to her maybe because of her ill character or caused by unfulfilled promise. While "Healing" as an archetype both in Kagan and universally signified for new life and beginning and blessing. The "Snake" archetype in Jungian interpretation symbolized pure force, evil, corruption, sensuality, destruction, mystery, wisdom, treachery and deceit. The "Snake transformation" generally in Kagan and universally displayed a symbolism of healing and miracle. The character in the poem Pobring Ganting who has healed the mother symbolized as the answer to their trouble. "Secret" on the other hand takes a symbolism as a weakness, downfall, destruction and unique quality. This secret symbol was related to the secret like the Achilles heel. The "Handkerchief" archetype signified for faith, fidelity, chastity and pureness. While on the one hand, "Tigers, Lions and Elephants", the Tiger signified courage and bravery; Lion symbolized strength, courage and bravery while Elephant signified for prosperity and luck. The "Cliff" symbol represented obstacles, troubles, new opportunity and tribulation. "Wild Chicken, Kingfisher and Hawk" individually these has its own symbolism, the wild chicken though it does not have a gender but in the bible this was characterized as a symbolism of an ideal maternal love and Christian love. The "kingfisher" symbolized peace, prosperity and love. According to the bible this was the bird to fly from Noah's ark. While, "hawk" was a symbol of high vision and order. The "Old woman" archetype in Kagan and in other countries this symbolized wisdom and honour. While "Bread" on the contrary, signified source of strength. Finally, "Transformation" symbolized blessing and a new beginning.

Guided by Blake (1954), this poetry using archetype is what we called as the language of allegory this became the foundation for a new critical understanding of literature. The framework of archetypal symbolism is to unify in our minds the symbolism of another poet, which is anchored to visionary symbolism (Frye, 2006). Presented below was a narrative poem of Kagan tribesmen. 
In the fifth Kagan poem entitled "Yang to ma Maglonon na mga Mimaylo"with an English translation of "The Three Orphan Siblings" was written in a narrative poem form, which tells a story about tree orphan siblings who were living with their aunt's house however they were maltreated by her. And so, they left her house and lived independently but because of their golden heart despite financially challenged, an old man gave them a magical ring which helped them to uplift their state of living and even raise their parents from death. Later on they have again met their aunt and they have forgiven her and live happily with their parents. Under archetypal criticism the following symbols were lifted: "Aunt", "Old man", "Oldest boy", "Water", "Ring", "Nice clothes", "Yellow", "Tomb", "Beautiful house" and "Celebration". Given the first symbol "Aunt", in many stories and literature was characterized as being terrible to their niece and nephew instead of being a second mother. Who was also having a persona and character of being witch with a dreadful aura. "Old man" has a symbolism of wisdom and the knowledge. The "Oldest boy" personified a symbolism of a second father when it comes to family responsibility. "Water" archetype held a symbolism of mystery of creation, birth-death resurrection, purification, redemption, fertility and growth. The "Ring" archetype, probably one of the famous symbol which was made popular by the movie Lord of the Ring was given a symbolism of mystery and the focal of power. "Nice clothes" directly symbolized social status and hierarchy. The color "Yellow" signified in Kagan as royalty which is associated to sunshine, hope and happiness. "Tomb" as a sacred structure where the dead are buried symbolized death, memories, soul, dark secret and connected to tragedy. While the "Beautiful house" carried a symbolism social status and stability in life. Lastly, "Celebration" was attributed to happiness, success and togetherness. This can be seen in most stories and movies and cultures who celebrate if something good happened or a victory has been achieved.

Consequently, archetypal patterns in poetry demonstrated ancient symbolism which is replicated in literary pieces across a long period of time such as Aeschylus, Dante's Inferno, Shakespeare's Hamlet, and Coleridge's The Ancient Mariner. Important to emphasize, certain poems hold with a special emotional significance through excitation of unconscious forces known as archetypes which were recurring, primordial, inherited images that determine as individual's present experience (Bodkin, 1965).

In the sixth Kagan poem entitled "Si Pastora Acubena" with an English translation of "Pastora Acubena" was written in a narrative poem form, which talked about this despised family by a datu. Pastora Acubena got sick and her mother Tamisa was told to bring her to the seventh mountain where a healer can help them and she was brought there. Indeed, she was healed and knowing that they were muslims the datu there accommodated them well and even help them through the use of a handkerchief. Pastora Acubena became the datu of their place and married the good datu's son. With that, the following symbolisms were elicited from this poem: "Sick", "Seventh mountain", "River of Jordan", "God", "Horses with wings", Golden palace", "Mosque" and "Gold".

First symbol in this poem "Sick" has a symbolic meaning of being a challenge, sacrifice, problem and symbolically connected to as reconnection to our divine creator. Next, the "Seventh mountain" symbolized in Kagan as a challenge or obstacle in life. Similarly, the number seven symbolized God and to follow God himself is a big challenge because we have to be morally upright and that does not as easy as what is seems to be. In literature, in the masterpiece of Dante Alighieri the number seven has a symbolic meaning since this was the last stage or place that the main character has to reach. And by that, this means that you have to pass six stages or obstacle before getting into your final destination. The "God" archetype both Kagan and different cultures signified as the only supreme being and the divine intervention. "Horses with wings" or Pegasus though was mythic creature has a symbolic meaning of a special vehicle of the mighty warrior which similarly signified for mightiness, liberty, divine force and of being enigmatic. The "Golden palace" symbolically signified for virtuosity, royalty and prosperity. It also symbolized fulfilment in life. The "Mosque" or church signified sacredness and a symbolic worshipping place for all Islamic people around the world. Finally, "Gold" though stands for prosperity and wealth it was related to blasphemy and wickedness because of what it can bring to people just to possess it. 
Furthermore, symbols were those of common to the majority and of the same meaning. Collective symbols for example which were common to all cultures and there was no likelihood and other interpretations were: sky father and earth mother, light, blood, up-down, the axis of a wheel and others. In like manner, imagination was the authentic contributor to the core nature of the world or viewing the particular as somehow embodying a more universal significance (Wheelwright, 1959).

In the seventh Kagan poem entitled "Si Sawopak" with an English translation of "Sawopak" was written in a narrative poem form, which basically narrated the story of this old couple who has no child before but were then given after praying from God. However, the child has only half body and when the boy got matured he then asked God for the other half of his body. This only happened if he has a clean liver and so, he got the other half of his body. From this poem after archetypal analysis has been made two major symbolisms were lifted: "Old couple" and "Child". An "Old couple" on one hand, signified in Kagan as someone who represent the state of being togetherness, a long lasting intimate relationship and someone who stood for the cultural heritage of a tribe. In connection to this in "Old couple" it is also association to being ordinariness, simplicity and a strong connection to each other. The last symbol "Child" signified in Kagan as the fruit of two in loved couple and a legacy, it also symbolized as the binder of the family. This in a broader sense the "Child" archetype symbolized innocence, impulsiveness and naivety.

The Kagan Tribe in Preserving their Poems. Having themes were already revealed from the second research question. These were discussed and interpolated among available and related studies. Propositions, claims and readings were the key points used to support each theme. In line with the first research question it was discovered that one way of poem preservation of Kagan was through Use poems as lullaby. It was pointed out that this was practiced to teach and bring people together. In which, this performances of poems as cradle songs or an oral art form does not only play to lull children to sleep but likewise, contributed to the upbringing, socialization and development of a child (Ntuli, 2013). Lullaby or cradle song helped Kagan parents to bring their children to sleep. It was through this they have transmitted their poetic songs to the young.

To state for a fact, Chuabbz (pseudonym) discussed during the interview that Kagan poems were presented to the young generations during sleeping time by singing these to them. An informal way of exposing these poems made them acquainted and later they be able to memorize the same. A time where they were comfortable made the activity more effective and less threatening environment. The practice of integrating poetry in lullaby among Kagan made the acquisition enjoyable being relevant to suggestopedia method in education. In like way, the repetitive singing these literary poems of Kagan to their children at an early state made them well accustomed with it. The application of poems in lullaby ensured its transfer of information and its survival for the next generation.

Given that theme with the related studies, it was further suggested that this result may be used for future studies to elicit feelings, emotions and ideas of other tribe. Next to it, the second theme under this research question was to Teach poems to the youth. Performance poetry developed creative self-expression and literacy among youth and at the same time built a literary culture and platform for social change. Accordingly, spoken words such as poems are with holistic effect like in social and psychological benefits, being accompanied with support and mentorship to them, while engaging them to community building. Poetry can be a vehicle for education (Bean \& Brennan, 2014). Teaching to the youth about the Kagan poems is a civil obligation of the Kagan elders to the youth. Direct teaching means as well the transfer of elders' skills, knowledge, beliefs, culture and tradition. In connection, Earnest (pseudonym) elaborated that cultural heritage was presented through the form of poetry. This improved comprehension and memorization of their literature. And most importantly, this became the vehicle for its preservation through the ages. Learning their poetry was as the same as conserving the pigment of the race.

In addendum to the same, the assurance of successful transmission of one's culture and tradition to the next offspring has greatly dependent on the correct practices of the predecessors. The challenge facing by these 
novels social learning, neighborhood dialects and other tribal poems when it was not carefully documented and worst if tribal elders have passed away. To present a good illustration was the African Oral Literature wherein, the imprint of those traditions were preserved through a perfect, in quality, historical value and viewpoint whereby Africans viewed themselves customarily and find solace despite serious social and different struggles (Finnegan, 2012).

Another theme emerged from the informants' information and experiences as member of Kagan tribe was Let children repeatedly recite the poems. Appreciation undeniably interconnected with an expression, the same as poetic gracefulness has something to do with verse exercises or reciting poems. A scrutiny of sonnets, which is under investigated, unlocked how to be grateful in poetry. In this manner, it figured out the way in composing, present and audit lyrics have been created. Critically performed this task, a reader understudy understand the verse implicitly and explicitly with full of gratefulness. In this state, the reader himself will put on the writer's shoes, wherein he or she can feel, empowers to ingest esteems in lyric, and acknowledges verse as show-stopper along with its magnificence or shortcoming (Morrison, 2012). Additionally, Maester (pseudonym) revealed that Kagan tribesmen repetitively taught their poems to the youth. Constant teaching of these folktales and songs to them frequently as possible and reciting these were the best way to instill to their young minds. Reciting the poems in an early age made the learning more possible and long lasting.

Lastly under the second research question Showcase the poems in social gathering and special occasion was one of those ideas highlighted during the data gathering. Direct learning was important to literature and culture acquisition while application of these has a meaningful projectile to its preservation. To provide a concrete example of poetry being showcased in special occasion, in a native Jewish or Muslims wedding is an extended celebration and all evenings were devoted to social gatherings. Poets and musicians recited three types of poetry on such occasions: poems related to event or to the young couple, the families, and the guests; secondly, religious poems which praised Israel as God's bride or poems which are irrelevant to the occasion; and finally, song of pastime which are connected to love. Thus, given this role of poetry in social gatherings and special occasions medieval Hebrews poems were actually recited or sung at weddings and other social gatherings (Goitein, 2010). Furthermore, as provided by Maester (pseudonym) Kagan people shown their appreciation and affection towards their poetry was through showcasing these during special occasions and festival their tribe has undertaken. It was during these events they found the best time to introduce to the community and most especially to the youth.

The Hopes of Kagan Tribe about their Poems, Literature in to their Race. To complete the purpose of this study, the last research inquiry was now to discuss through interweaving from related readings, propositions and studies. Provided during the interview and discussion of informants under the last research question, Poems and literature be preserved was one of the main aspirations of Kagan for their literary heritage. Poetry and literature were the vehicle in propagating cultural values, preserving local history and heritage, protesting against ills and stimulating reforms in the society. However, culture was under serious threat from constant incursion of foreign media the same is to poems and literature. And so, oral traditions transformed into writing as a result of western education. Such for instance, in African poems and literature have putted from oral to written lore, which has an advantage of preserving the deep cultural undertone of Yoruba poetry, and that of Africa by extension (Falade, 2013). Relative thereto, Healer (pseudonym) emphatically stated that in order to preserve our poetry and literature, everybody was urged to teach these to the children and to their coming children and likewise allowed them to participate in any tribal occasions and celebration. Because it was during these times they will be able to learn and acquire important traditions of the tribe.

One of the hope of Kagan tribesmen was Literature be handed down from generation to another generations, accordingly it was such this action will effectively preserve their literature. Significantly, handing over from generation to the next of different forms of culture was vital to secure its preservation; this was done through oral literature which was useful in so many ways to a tribe. By this practice, human behaviors and characters before were saved such as: social trusts esteems, capabilities, knowledge and the vast historical 
phenomena of the society. Thus, the oral tradition will help the future to acquire and learn the things that have been done before and still perform the same (Kothari, 2014).

Significantly, Shyness (pseudonym) stressed in her statement that she hoped to handed these down all of what she has acquired and learned may continue by her children and the Kagan people. Bring about from the participants' experiences was Continuously educate the youth about Kagan literature and practices this has efficiently carry out the conservation of Kagan's literature and practices for the new generation. Moreover, education enabled indigenous youth to exercise and enjoy economic, social and cultural rights and strengthening their ability to exercise civil rights in order to influence political policy processes for improved protection of human rights. The implementation of indigenous peoples' right to education was an essential means of achieving individual empowerment and self-determination. Education was also as important means for the enjoyments, maintenance and respect of indigenous culture, languages, traditions and traditional knowledge. It was the primary means of ensuring indigenous peoples' individual and collective development; it was a precondition for indigenous peoples' ability to realize their right to self-determination, including their right to pursue their own economic, social and cultural development (Champagne, 1987).

Earnest (pseudonym) revealed that constant teaching them about their practices in order for them to fully understood and retain to their mind all of these. It was also highlighted by the Kagan informants the Use modern technology as archive of Kagan literature. The tensions and challenges for preservation of literature embraced the quantum of digital resources, mass digitization and its effects on the longevity of collections, increased awareness of risk management and disaster response, the need for digital preservation and curation, and the changing focus on preservation education in the digital age. Furthermore, the future of the preservation field specially in literature lied in effective implementation of digital technologies for collection building, strong leadership in standards and best practices development, and careful management of resources to continue to care for print collections and give increased attention to those materials that most need our attention such as audiovisual and born-digital materials (Gracy \& Kahn, 2009). To connect, Sophie (pseudonym) informed that these modern technologies have positive results in terms of preserving and protecting the poems, literature and culture. Through these, the new generation utilized, read and understood things which were handed down from them by their ancestors.

In relation to research question, another theme was Kagan's cultural identity as tribe be reflected in poems as being agreed poetry became the manifestation of Kagan's unique cultural identity. Autobiographical poetry as a representation of one's cultural background offers flexibility in form and content. This allows them to articulate memories, define their identities and tap into the social literacies of their linguistic communities. Present in this manner are home codes and the home cultures, auto biographical poetry may contribute to bridging dichotomies among contrasting cultural models and literary practices and creating more inclusive learning spaces. By this, individual background aligns linguistically and thematically based on the experiences, discourses, engage their varied social literacies, and experiences literacy in its most authentic forms (Cibils \& Marlatt, 2019). As affirmed both by Protectress and Elderly (pseudonym) that Kagan poems were unique when it comes to tone, accent and the way these have been delivered were prolong in intonation. As added by Sophie (pseudonym), through our poems it can be expressed the Kagan identity such as beliefs, practices, values and livelihood.

Lastly, revealed from the respondents' sentiments and beliefs that Kagan literature and cultural practices be appreciated. Literature and culture appreciation among can be illustrated through the phenomenon that people for centuries have felt the need to express their opinion on things and events happening around them and to them, which can be seen through literary compositions. Thus, an imaginative literature proved to be one of the most vital tools to reflect the happenings around us. In light thereto, literature was a reflection of culture and society, portraying people's ideas and dreams set in a certain time and space frameworks in most creative and imaginative way. Further illustrated, it presents social changes and is often treated as credible source of culture representation (Habbar, 2020). This was confirmed by Guru (pseudonym) she prayed that all of the Kagan 
practices will always remain in their mind and hearts as they go along with their respective journey and continue to perform these. Because these were the treasures of the tribe handed down by our great ancestors.

Wherefore, the role of poetry in Kagan life significantly contributed to the entirety of their cultural imprint as an indigenous people. As I mentioned in the rationale and purpose of the study, since poetry was a the reflection of Kagan's feelings, emotions, thoughts, experiences, culture and tradition these have to be officially documented in the soonest possible. As much as elders and cultural masters are still alive and ready to hand over the information and wisdom they possessed. In connection, alarming concern at hand was the continuous and no action to these undocumented and unrecorded literary works of our indigenous people. As a steward of our native root, these body of literature must be secured purposely of proliferating throughout generations but, sad to unveil it has been neglected and being gradually forgotten as the year changes. Therefore, crisis in tribal communities when elders die and likewise together with the language and literature of the ethnic group (Alexander, 2013). Furthermore, unanimously of their responses that repetitive or direct teaching to the youth was one of the key in its preservation. Tita (pseudonym) supported the idea that constant teaching to the young generation will assure its proliferation. She further added that their deep love to their written poems were overwhelming and practice by doing do influenced the youths' learning towards their poems.

\subsection{Implication in Language Teaching}

From the result of archetypal analysis undertaken about the selected Kagan poems, archetypes and symbolisms emerged such as sweetheart, far place, heart, marriage, work, melancholy, lover, resume our loving, return our past, past days, learning of our love, happiness of my heart, strength of my body, life, world, feast, days and nights, trouble, worlds is passing by, death, wife got sick, healing, snake, snake transformation, secret, handkerchief, tigers, lions and elephant, cliff, wild chicken, kingfisher and hawk, old woman, bread, transformation, aunt, old man, oldest boy, water, ring, nice clothes, yellow, tomb, beautiful house, celebration, sick, seventh mountain, river of Jordan, God, horses with wings, golden palace, mosque, gold, old couple and child. With these signifiers and being signified, disclosed the association of these symbols to the things that surround them such as those related to their custom, tradition and culture. This further unveiled that symbolisms in their poetry achieved universal interpretation which conforms to archetypal criticism.

Likewise, the result of the study resonated to the educational institutions and public offices like the NCIP and CCCAD. They will be given the drive to conduct related and another facet of the Kagan tribe such to delve the multiple perspective of the Kagan practices, beliefs, historical background and literature. It is humbly offered the archetypal analysis made in the study to use as a basis to understand and decode literary pieces of Kagan people. Moreover, this will open for other feasible activity that promotes poetry and literature preservation. As well as, this rippled to the academe especially teachers of Philippine literature. This will provide ideas and background about the Kagan tribe specifically about their poetry and symbolisms and how these should be effectively taught to the learners.

\subsection{Implication for Further Research}

Members of the ethnic community are the hidden keys to the secret of our civilization. It is through them we had able to uncover the mystery of our yesterday. Their poetry and literature are the manifestation of their creative prowess in writing which reflected unique behavior and their history. Given the results from the research questions, interviews and discussions provided us with a better understanding about the Kagan poetry and culture. The Kagan poems mirrored their rich cultural identity as part of the Muslim community. Kagan tribesmen used their poetry in multitude ways for preserving their tradition and old practices. Kagan language directly represents the tribe itself and the people. They used of language made distinct among any other Muslim group. Hence, language and structure depict sociolinguistic uniqueness. The continuous undocumented of Kagan literature and practices may result to its complete extinction. However, gladly to discover that there were some ways Kagan people were doing in order to avoid the former scenario. The process of inculcating to the young 
minds of these literary and linguistic identities of the tribe ensures its sanguine future. Further, showcasing these in Kagan celebrations and gatherings afforded to thrive amidst this technological age. Indeed, advanced technologies itself became the repertoire of their cultural and literary information. Henceforward, future researchers are encouraged to continue investigate for further undertakings that will promote cultural diversity and literary conservation not only among Kagan tribesmen but also other ethnic groups

The aspirations of Kagan tribesmen were simple and yet challenging. It was clear that they aimed to preserve their cultural practices and poetry. They aspired to let the youth felt ethnic pride towards their identity as Kagan. A sense of deep appreciation for their customs and traditions were things they emphasized among them. These pose a huge challenge, how the elders will be able to pursue and make these possible. With these, I strongly encouraged new researchers and the youth to be the forerunner in studying other tribes regardless if you are a member of them. It is our civic obligation to safeguard the natives of our race. Moreover, I took the challenge of studying the Kagan tribe despite of being a non-member of the group. Accepting the quest, I found the ideals of doing future researches which delve on their cultural practices that are unique to them. The risk of doing the tedious process is worth the result and thus, I encourage further researchers to discover new perspectives about Kagan and other ethnic groups. Furthermore, we owe to our native people the society of today and our future. There is no enough reasons to urge future researchers to further discover and investigate the root of our ethnic groups because this is our patriotic obligation to our fatherland.

\subsection{Concluding Remarks}

Working on my research title was literally a struggle. When I defended my title it was a total failure because of some issues that might cause complication in the future. And finally, I was inspired by my college classmate and friend who is by the way belong to this subgroup. I was curious and enthusiastic to study about the Muslim culture and literature. Because more often than not, other researchers and even ordinary people were frightened and have this negative background about the Muslim people. Muslims were victim of society's stereotyping. And so, I have decided to take responsible in studying the group especially their poetry. Gathering the general information and background of the tribe was one of the most challenging facets of the study. I knew for a fact, that this was one of those difficult things that I have to surpass. And I am grateful of the book published by the City Government of Tagum thru its City Cultural Communities Affairs Division - Kagikan.

Moving on, discouragements and negative feedbacks in this endeavor were not a hindrance but rather an inspiration to accomplish this material. The tedious processes that I undertook plus the requirements that I have to comply both in Graduate School and in NCIP and CCCAD were tiresome. However, as they say when there is a will there is always a way. To add more, I am currently employed in an environment where Muslim people were living. And as every day I have been encountering them, I found the interest about this subgroup named Kagan. This became familiar to me because of my college friend. As I was exposed to them, I became acquainted of their language and speech delivery. And little by little through my gatekeeper who was fluent both on the Kagan language and English language I had possibly understood their poetry and conversations. As well, she has introduced to me some of their common vocabulary.

More of I discovered was the stigma of racial discrimination among Muslim which was not limited to Kagan tribesmen. The story unfolded was the discrimination of lending companies who tend to refuse if known that client was a Muslim. The same stereotyping was happened in this certain area in Tagum City where known to be the cradle of illegal activities and goons which apparently the opposite thing. The misconception that the moment you enter to this place means no turning back home was completely a myth. Rather, the people were accommodating and hospitable. These were just some of the destructive attributes to them. In conducting this research inquiry, I made to prove them wrong and widen my knowledge about the group. After the analysis of the identified corpora, it was found out that the archetypal feature of Kagan poems have cultural significance and the interpretations are the same to other cultures, literature and common to human unconscious. Therefore, this conforms to the archetypal approach definition that a symbol can only be considered as an archetype only if it is 
recurrently used and with the same interpretation in literature; generally accepted among other cultures and ethnicities and collective to human unconscious.

Wherefore, their magnificent literary pieces and rich cultural heritage afforded me to initiate investigation of their tribe. Their uniqueness as an ethnic group paved to conduct an archetypal analysis of their poetry. The distinctiveness of their culture as seen in their poetic traditions were stories need to be kept and documented. Given the formal and informal practices in literature and culture preservation coupled with their hopes strongly suggested the love and pride for their tribe towards these. In like manner, this will break the wheel about negative stereotyping among Kagan and hopefully to the entire Muslim community. To connect, William Wordsworth said "Poetry is the first and last of all knowledge - it is immortal as the heart of man".

\section{References}

Alexander, J. (2013). The civil sphere. Oxford: Oxford University Press, Oxford, England.

Amparo, A. (2011). Teaching and learning terminology. New strategies and methods. John Benjamin Publishing, Amsterdam, The Netherlands.

Ariola, M., \& Buendia, J. (2013). Principles and methods of research (1 ${ }^{\text {st }}$ Ed.) Rex Printing Company Inc., Quezon City, Philippines.

Atkinson, P., Coffey, A., \& Delamont, S. (2011). Handbook of ethnograpy, London: Sage.

Augustyn, A. (2018). New criticism. Encyclopedia Britannica, Inc. Retrieved from https://www.britannica.com/art/New-Criticism

Backhouse, G. (2012). How preserving confidentiality in qualitative health research can be compatible with preserving data for future use. Medical Sociology News, 28(3), 32-35.

Baloyo, M. (2019). Personal interview. (A. Logronio, \& J., Saclot, Interviewers). Tagum City, Davao del Norte, Philippines.

Barsalou, L.W., \& Carcary, M. (2015) The instability of graded structure: implications for the nature of concepts. Cambridge University Press, Cambridge, United Kingdom.

Bartle, R. (2010). British social attitudes: The $20^{\text {th }}$ report, 223.

Bascom, W. (2012). The forms of folklore: Prose narratives. Journal American folklore, 78(307), 3-20. https://doi.org/10.2307/538099

Bayotas, M. D. (2004). What's in a name? The Kagan ethnicity and identity. UP Mindanao, Philippines.

Bean, E., \& Brennan, K. R. (2014). Youth voices: performance poetry as a platform for literacy, creativity and civic engagement. Journal of Applied Research on Children: Informing Policy for Children at Risk. Vol. 5: Iss. 1, Article 23.

Bernal, G., \& Rodriguez, D. (2014). Tailoring treatments to patient's race and ethnicity. In G. P. Koocher, J.C. Norcross \& B.A. Green (Eds.), Psychologists' desk reference, Third Ed.(pp.310-313). New York \& London: Oxford.

Biddle, A. W., \& Fulwiler, T. (1989). Reading, writing, and the study of literature. Random House, New York, USA. 75-84, 100.

Blake, W. (1954). Symbol and Image. Oxford: Clarendon Press, Wotton-under-Edge, UK.

Bloom, B., \& Crabtree, B., Kombo, P. (2014). Making sense of qualitative research: The qualitative research interview. Blackwell Publishing Ltd, Oxford, UK.

Bodkin, M. (1965). Archetypal Patterns in Poetry. Oxford University Press. London, UK.

Borden, R.C., \& Biklen, S.K. (1992). Qualitative research for education: An introduction to theory and methods. Boston: Allyn \& Bacon. Retrieved from books.google.com.ph/books/about/Qualitative_Research_for_Education:

An_introduction_to_theory_and_methods

Boyatzis, R. E., Mark, J., \& Biklen, N. (2012). Transforming qualitative information: Thematic analysis and code development. Sage Publishing, California, USA.

Brown, J. (2010). Training needs assessment; a must for developing an effective training program public 
personal management 31: 569574. Sage.

Burns, N., Grove, S., \& Miles, B. (2015). Understading nursing research: Building an evidence-based practice, 60-96.

Byatan, A., \& Indie, A. (2018). Personal interview. (City Government of Tagum). Tagum City, Davao del Norte, Philippines.

Caplan, D. (2011). Questions of Possibility: contemporary poetry and poetic form. Oxford. Uk; New York: Oxford University Press, Oxford, UK.

Champagne, A. (1987). The Sage Handbook of Cultural Sociology. Sage.

Chesaina, M., \& Topolski, D. (2011). One last chance: Tapping indigenous knowledge to produce sustainable conservation policies, 989-998. Retrieved from http://library.sprep.org/Pein/content/Detail.aspx?

Cibils, L., \& Marlatt, R. (2019). Poetry and culture identity: A sociocultural approach for teacher education classrooms, Action in teacher education, 41:2, 137-153. https://doi.org/10.1080/01626620.2019.1600599

City Government of Tagum. (2019). Kagikan: Tracing the flow of Tagum's rich history. Tagum City, Davao del Norte, Philippines. City Government of Tagum through City Historical, Cultural and Arts Council Publishers.

Collier, P., \& Helga, G. R. (2010). Literary Theory Today. Ithaca: Constitutional Challenge to the Indegenous Peoples' Rights Act of 1997. Cornell University Press.

Colton, A., \& Covert, A. (2013). The wild tribes of Davao, Chicago: Field Museum of Natural History. Bibliolife DBA of Bibilio Bazaar II LLC.

Cook, G. (2010). Goals and Plans in Advertising and Literary Discourse, in Parlance.

Cranston, E. (2012). The Seidensticker Genji: Rev. of the tale of Genji by Murasaki Shikibu; Edward Seidensticker. Journal of Japanese Studies. 4.7.

Creswell J. W., \& Miller, D. (2000). Determining validity in qualitative inquiry. Theory into practice, 39(3), 124-130. SAGE.

Creswell, J. (2013). Qualitative inquiry and research design: Choosing among five approaches (3 ${ }^{\text {rd }}$ ed.). Thousand Oaks, CA: Sage.

Creswell, J. (2014). Research Design: Qulalitative, Quantitative, and Mixed Methods Approches (4 ${ }^{\text {th }} \mathrm{Ed}$.). SAGE.

Creswell, J. W., \& Brown, M.L. (1992 Fall). How chairpersons enhance faculty research: A grounded theory study. The review of higher education, 16(1), 41-62. SAGE.

Creswell, J., \& Miller, D., Woodsong, S. (2011). Theory into practice college of education, The Ohio State University.

De Saussure, F., (1966). Course in general linguistics. McGraw-Hill.

De Vera, D., (2007). Indigenous peoples in the Philippines: A case study. Hanoi. Vietnam.

Delahoyde, M. (2011). Literature: archetypal criticism. WSU. Washington State University, Washington DC, USA.

Denzin, N.K., \& Lincoln, Y.S. (2011). Introduction: The discipline and practice of qualitative research. The Sage handbook of qualitative research. SAGE.

Digby, G. F. W. (1957). Symbol and image in William Blake. Oxford: Clarendon Press.

Dornyei, Z. (2010). Research methods in Applied Linguistics quantitative, qualitative, and mixed methodologies. Oxford: Oxford Publishing.

Eugenio, D., (2007). The Epic., Vol. 3 Edition, University of the Philippines, Diliman, Quezon City.

Falade, K. (2013). Yoruba culture abhors suicide. National Mirror.

Famindang, A. (2018). Personal Interview. (City Government of Tagum). Tagum City, Davao del Norte, Philippines.

Fansler, D., \& Pasio L. (2014). Philippine folk literature: A synoptic study of an Unpublished.

Finnegan, R. (2012): Oral literature in Africa: Open Book Publishers.

Frye, N. (2006). The archetypes of literature. The Educated imagination and other writings on critical theory 1933-1963. Ed. Germaine Warkentin. Toronto: University of Toronto Press. 
Literary poetic tradition: An archetypal analysis of selected Kagan poems

Frye, N. (2006). Anatomy of Criticism: Four Essays (Denham R., Ed.). University Of Toronto Press, Toronto, Canada. Retrieved from http://www.jstor.org/stable/10.3138/j.ctt2tth1v

Gibbs, G.R. (2007). Analyzing qualitative data. In U. Flick (Ed.), The Sage qualitative research kit. Thousand Oaks, CA: Sage.

Gioia, D., \& Gioia, K., (1995). Literature: An introduction to fiction, poetry, and drama, $6^{\text {th }}$ Ed., New York: HarperCollins, 1995. Pages 1790-1818.

Giorgi, A. (2009). The descriptive phenomenological method in psychology: A modified Husserlian approach. Pittsburgh, PA: Duquesne University Press.

Goitein, S.D. (2010). Studies in islamic history and institutions. Vol. 5. Brill.

Gowing, P. (1984). “Kalagans.” In Muslim Peoples: A World Ethnographic Survey, Edited Weekes, R., 367. Westport, Conn.Greenwood Press.

Gracy, K.F., \& Kahn, M.B. (2009). Preservation in the digital age: A review of preservation literature. Retrieved from https://journals.ala.org/index.php/lrts/article/view/5495/6745

Greene, C.J., \& Caracelli, V.J., (Eds.). (1997). Advance in mixed-method evaluation: The challenges and benefits of integrating diverse paradigms. (New Directions for Evaluation, No. 74). Jossey-Bass.

Guerin, W., Labor, E., Morgan, L., Reesman, J., \& Willingham, J. (2010). A Handbook of Critical Approches to Literature. $6^{\text {th }}$ Ed., Oxford University Press.

Guest, G., MacQueen, K. M., \& Namey, E. E. (2012). Applied thematic analysis. Thousand Oaks, CA: Sage.

Habbar, A. (2020). Connection between culture and literature. Retrieved from https://academia.edu/21327755/Connection_Between_Culture_And_Literature

Hatch, J. A. (2002). Doing qualitative research in educational settings. Albany: State University of New York Press.

Holden, W., Nadeau, K., Jacobson, R. P. \& Lanzaga, K. (2011). Exemplifying Accumulation by dispossession: mining and indigenous peoples in the Philippines. Geografiska Annaler: Series B, Human Geography.

Institute of National Language Ministry of Education, Culture and Sports, (1984). Mga Oman-oman ng mga Kalagan. A collection of Kalagan folktales and poetry. Summer Institute of Linguistics-Philippines.

Jung, C. G. (1955). Time: The weekly news magazine. August 7, 2019. Retrieved from https://content.time.com/time/covers/0,16641,19550214,000.html

Jung, C. G. (1968). The Archetypes and the Collective Unconscious. 2nd ed. London: Routledge, London, UK.

Jung, C. G., \& Franz, M.L. (1968). Man and his symbols. Dell Publishing Co.

Kothari, A., Demaria, F., Acosta, A., Avancena, M., Fuentes, P., \& Dela Cruz, K. (2014). Degrowth and ecological alternatives to sustainable development and the green economy: Development 57: 362-375.

Lapan, A. (2018). Personal Interview. (City Government of Tagum). Tagum City, Davao del Norte, Philippines. Lincoln, Y., \& Guba, E. (2012). Naturalistic inquiry. Newbury Park, CA: Sage.

Lobos, D.D. (2000). Patterns of growth and change among the Kalagan in Madaum. Tagum City, Philippines.

Locke, L. F., Spirduso, W.W., \& Silverman, S. J. (2013). Proposals that work: A guide for planning dissertations and grant proposals (6 ${ }^{\text {th }}$ ed.). Thousand Oaks, CA: Sage.

Makaigad, P. (2018). Personal Interview. (M.C. Pagdilao, \& C. Valenzuela, Interviewers) Hijo, Maco, Compostela Valley, Philippines.

Maree, K., Van Der Westhuizen, L., \& Marryin. (2012). Planning research proposal. First steps in research. Pretoria.

Marshall, C. \& Rossman, G. B. (2011). Designing qualitative research (5 ${ }^{\text {th }}$ ed.). Thousand Oaks, CA: Sage.

McCullough, D., William, H. \& Lester, O. (2010). Japanese Marriage Institutions in the Heran Period. Hardvard Journal of Asiatic Studies, 27.

Merriam, S. B. (1998). Qualitative research and case study application in education. San Francisco: Jossey-Bass. Retrieved from searchworks.stanfords.edu/view/3511521

Miles, M. B. \& Huberman, A. M. (1994). Qualitative data analysis: An ethnogragphy. Unpublished doctoral dissertation, University of Nebraska-Loncoln.

Miller, D. C., \& Salkind, N. J. (2002). Handbook of research design and social measurement (6 $6^{\text {th }}$ ed.). Thousand Oaks, CA: Sage. 
Morris, I. (2011). As i crossed a bridge of dreams. Penguin Books.

Morrison, A.D. (2012).'Performance, re-performances, and Pindar's audiences', in Agocs, Carey, and Rawles (2012a): 111-33.

Moustakas, C., \& Grempes, V. (2014). Phenomenological research method, Thousand Oaks, CA. Sage.

Nelson, L. (1974). A comparative analysis of Archetypes in T.S. Eliot and Nathanael West. Burdick, Kansas. Master's Thesis. Retrieved from esirc.emporia.edu

Ntuli, C. D. D. (2013). Children's oral poetry: A reflection on the role of Imilolozelo (lullabies) as art performance in Zulu. Journal of Music Research in Africa. Vol. 10, 2013 - Issue sup1: Supplement. https://doi.org/10.1080/18125980.2013.85

O’neill, R., \& Maccion, L. (2012). Why use textbooks. ELT Journal.

Omari, H., \& Fuentes, V. (2010). A treasure of Mandaya and Mansaka folk literature. Quezon City, Philippines. Patton, M. (2012). Describing camp talk: Language/pragmatics/politics. Language and Literature 9(3): 240-60.

Peloton, M.A. (2001). A study of the consequences of urbanization in the Kalagan community. Retreved from www.mdpi.com.

Pongo, B. E., \& Bungad, A. (2018). Personal interview. (M.C. Pagdilao, \& C. Valenzuela, Interviewers) Madaum, Tagum City, Davao del Norte, Philippines.

Poraz, J. W. B. (2001). Historical account of Kagan. (narrated account). Tagum City, Philippines.

Porter, S. (2011). Nursing research conventions: Objectivity or obfuscation? Journal of Advanced Nursing, 143. Retrieved from pubmed.ncbi.nlm.nih.gov

Raagas, E.L. (2010). Understanding research basic concepts (with computer approaches to basic data analysis), Iwag Printing Publication, Cagayan de Oro, Philippines.

Rossman, G., \& Rallis, S. F. (2012). Learning in the field: An introduction to qualitative research ( $3^{\text {rd }}$ ed.). Thousand Oaks, CA: Sage.

Rothenberg, J. (2011). Avoiding technological quicksand: Finding a variable technical foundation for digital preservation. Washington, D. D., Council on Library and Information Resources. Washington DC, USA.

Said, B., \& Toolan, M. (2010). Verse structure in Hausa poetry, literature and culture. Retrieved from books.openedition.org

Schorer, M. (1968). “The Necessity of Myth.” Myth and Mythmaking. Henry Murray, ed. Boston: Beacon Pres.

Schwandt, T. A. (2015). Sage dictionary of qualitative inquiry ( $3^{r d}$ Ed.). Thousand Oaks, CA: Sage.

Silverman, D., \& Green, T. (2010). Doing qualitative research: a practical handbook. SAGE.

Tarigan, H. (2014). Penerbit angkasa. Languages of the world.

Tiu, M.D., (2005). Reconstructing History from Text and Memory. Ateneo de Davao University Research and Publication Office for the Mindanao Coalition of Development NGOs.Davao City, Philippines.

Turin, M., Champagne, K., \& Pingel, D. (2013). Indigenous peoples and the Millinium Development Goals. Indigenous Perspectives, 7.1.

Walcott, H. T. (1994). Transforming qualitative data: Description, analysis, and interpretation. Thousand Oaks, CA: Sage.

Walker, S. F. (2002). Jung and the Jungians on Myth. NY: Routledge.

Watts, A. (1968). Myth and ritual in Christianity. Beacon Press.

Wheelwright, P. (1959). The burning fountain: A study in the language of symbolism. Bloomington: Indiana University Press, Bloomington, Indiana, USA.

Woodsong, C., Mack, N., MacQueen, K., Guest, G., \& Namey, E. (2011). Qualitative Research Methods: A data collector's field guide. USAID.

Yu, A. L. (2017). Folk Epics: An Exploration of Kagan Culture. International Journal of Education Research for Higher Learning, 23. Retrieved from https://ejournals.ph/article.php?id=13364 